\title{
Sustainability Assessment of Coal- Fired Power Plants with Carbon Capture and Storage
}

SH Widder

ML Elliott
RS Butner

CJ Freeman

October 2011
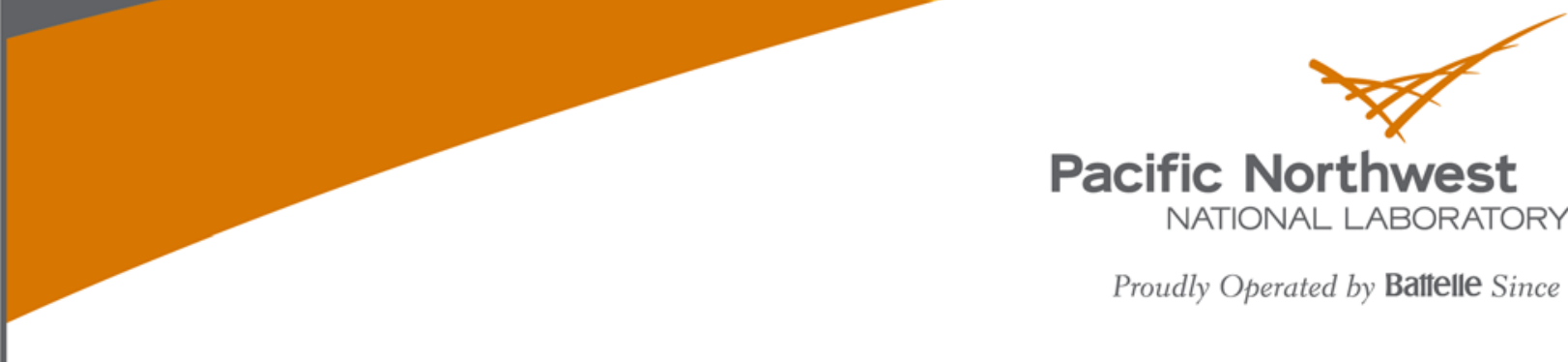

Pacific Northwest

NATIONAL LABORATORY

Proudly Operated by Battelle Since 1965 


\title{
DISCLAIMER
}

This report was prepared as an account of work sponsored by an agency of the United States Government. Neither the United States Government nor any agency thereof, nor Battelle Memorial Institute, nor any of their employees, makes any warranty, express or implied, or assumes any legal liability or responsibility for the accuracy, completeness, or usefulness of any information, apparatus, product, or process disclosed, or represents that its use would not infringe privately owned rights. Reference herein to any specific commercial product, process, or service by trade name, trademark, manufacturer, or otherwise does not necessarily constitute or imply its endorsement, recommendation, or favoring by the United States Government or any agency thereof, or Battelle Memorial Institute. The views and opinions of authors expressed herein do not necessarily state or reflect those of the United States Government or any agency thereof.

\author{
PACIFIC NORTHWEST NATIONAL LABORATORY \\ operated by \\ BATTELLE \\ for the \\ UNITED STATES DEPARTMENT OF ENERGY \\ under Contract DE-AC05-76RL01830 \\ Printed in the United States of America
Available to DOE and DOE contractors from the Office of Scientific and Technical Information,
P.O. Box 62, Oak Ridge, TN 37831-0062;
ph: (865) 576-8401
fax: (865) 576-5728 \\ email: reports@adonis.osti.gov \\ Available to the public from the National Technical Information Service \\ 5301 Shawnee Rd., Alexandria, VA 22312 \\ ph: (800) 553-NTIS (6847) \\ email: orders@ntis.gov <http://www.ntis.gov/about/form.aspx> \\ Online ordering: http://www.ntis.gov
}




\title{
Sustainability Assessment of Coal- Fired Power Plants with Carbon Capture and Storage
}

\author{
SH Widder \\ RS Butner \\ ML Elliott \\ CJ Freeman
}

October 2011

Pacific Northwest National Laboratory

Richland, Washington 99352 



\section{Summary}

Carbon capture and sequestration (CCS) has the ability to dramatically reduce carbon dioxide $\left(\mathrm{CO}_{2}\right)$ emissions from power production. Most studies find the potential for 70 to 80 percent reductions in $\mathrm{CO}_{2}$ emissions on a life-cycle basis, depending on the technology. Because of this potential, utilities and policymakers are considering the wide-spread implementation of CCS technology on new and existing coal plants to dramatically curb greenhouse gas $(\mathrm{GHG})$ emissions from the power generation sector.

However, the implementation of CCS systems will have many other social, economic, and environmental impacts beyond curbing GHG emissions that must be considered to achieve sustainable energy generation. For example, emissions of nitrogen oxides $\left(\mathrm{NO}_{\mathrm{x}}\right)$, sulfur oxides $\left(\mathrm{SO}_{\mathrm{x}}\right)$, and particulate matter (PM) are also important environmental concerns for coal-fired power plants. If the parasitic energy consumption of a carbon-capture plant increases the emissions of one or many of these other air pollutants, this should be considered when evaluating the technology's overall sustainability or environmental impact. While the majority of these "external" or "tangential" impacts are small on a global scale, it is still important to consider them to ensure the successful and sustainable implementation of CCS technology on a large scale. For example, several studies have shown that eutrophication is expected to double and acidification would increase due to increases in $\mathrm{NO}_{\mathrm{x}}$ emissions for a coal plant with CCS provided by monoethanolamine (MEA) scrubbing. Potential for human health risks is also expected to increase due to increased heavy metals in water from increased coal mining and MEA hazardous waste, although there is currently not enough information to relate this potential to actual realized health impacts. In addition to environmental and human health impacts, supply chain impacts and other social, economic, or strategic impacts will be important to consider. For example, if 90 percent of all the $\mathrm{CO}_{2}$ generated by coal plant in the United States was captured and stored, using an MEA process, the annual consumption of MEA by U.S. power plants alone would be approximately 3.6 million tons, or 9 times the current U.S. consumption. Although 100 percent adoption of CCS by U.S. coal plants is not a realistic scenario, the exercise illustrates that the potential magnitude of the MEA demand created by more realistic adoption rates.

Proper life-cycle assessments or analyses (LCAs) that are inclusive to all aspects of sustainability are a necessary tool for quantifying risk and feasibility of large-scale implementation of CCS. Life-cycle assessments have proven their usefulness in other systems, for example the sustainability of biofuels. For example, corn ethanol was championed as an alternative to importing foreign oil and a green way to increase rural employment. However, the competition of corn ethanol with food crops, its water use, and carbon debt were not well understood. If a full LCA or similar sustainability assessments had been done, these issues could have been identified earlier and the overall impact of corn ethanol could be more accurately compared to other biofuel options. As this example shows, sustainability assessments serve an important role in evaluating complex sustainability systems, like CCS, and can lead to a more accurate evaluation of all aspects of sustainability, even those outside of the usual boundaries of the process economic evaluation.

A thorough review of the literature for life-cycle analyses of power generation processes using CCS technology via the MEA absorption process, and other energy generation technologies as applicable, yielded large variability in methods and core metrics. This was not unexpected because, life-cycle analysis studies are drawn from multiple sources, have different scopes and goals, and their underlying assumptions tend to complicate the direct comparison or aggregation of data. Other literature has noted 
the variability between studies can be quite large, even for core metrics of performance such as the reduction in GHG potential. Comparison of the evaluated studies is further complicated by data gaps and lack of agreement on the way the data are presented.

Nonetheless, a few key areas of impact for CCS were developed from the studies that we reviewed. These are:

- the impact of MEA generation on increased eutrophication and acidification from ammonia emissions and increased toxicity from MEA production

- the impact of increased coal use including the increased generation of $\mathrm{NO}_{\mathrm{x}}$ from combustion and transportation, impacts of increased mining of coal and limestone, and the disposal of toxic fly ash and boiler ash waste streams.

Overall, the implementing CCS technology could contribute to a dramatic decrease in global GHG emissions, while most other environmental and human health impact categories increase only slightly on a global scale. However, the impacts on human toxicity and ecotoxicity have not been studied as extensively and could have more severe impacts on a regional or local scale. More research is needed to draw strong conclusions with respect to the specific relative impact of different CCS technologies. Specifically, a more robust data set that disaggregates data in terms of component processes and treats a more comprehensive set of environmental impacts categories from a life-cycle perspective is needed. In addition, the current LCA framework lacks the required temporal and spatial scales to determine the risk of environmental impact from carbon sequestration. Appropriate factors to use when assessing the risk of water acidification (groundwater/oceans/aquifers depending on sequestration site), risk of increased human toxicity impact from large accidental releases from pipeline or wells, and the legal and public policy risk associated with licensing $\mathrm{CO}_{2}$ sequestration sites are also not currently addressed.

In addition to identifying potential environmental, social, or risk-related issues that could impede the large-scale deployment of CCS, performing LCA-based studies on energy generation technologies can suggest places to focus our efforts to achieve technically feasible, economically viable, and environmentally conscious energy generation technologies for maximum impact. For example other, less impactful sources of parasitic energy or non-solvent based carbon-capture strategies. 


\section{Acknowledgments}

This report was compiled as part of a Laboratory Directed Research and Development (LDRD) project focused on finding new ways to address the multiple emissions streams from coal-fired power plants. Sarah Widder served as the manager for the sustainability assessment portion of this task and is the lead author on this report. Scott Butner also contributed substantially to the report and analysis. The authors are grateful to Mike Elliott, as the project manager for the entire Integrated Emissions LDRD, for recognizing the importance of sustainability assessment, and providing funding for the completion of this research. The authors would also like to acknowledge Ted Tenasse, who assisted in graphic

development; Charlie Freeman, Gary Josephson, and George Muntean, who provided technical oversight; and Lesley Snowden-Swan, Cassie Davidson, and Bob Dahowski, who served as subject matter experts and reviewers. 



\section{Acronyms and Abbreviations}

\begin{tabular}{|c|c|c|c|}
\hline \multirow[t]{2}{*}{$\begin{array}{l}\text { ADP } \\
\text { AIChE }\end{array}$} & $\begin{array}{l}\text { abiotic depletion potential } \\
\text { American Institute of Chemical }\end{array}$ & ISO & $\begin{array}{l}\text { International Organization of } \\
\text { Standardization }\end{array}$ \\
\hline & $\begin{array}{l}\text { American Institute of Chemical } \\
\text { Engineers }\end{array}$ & LCA & life cycle assessment/analysis \\
\hline AP & acidification potential & LCSEA & Life-Cycle Stressor-Effect \\
\hline $\mathrm{B}(\mathrm{a}) \mathrm{P}$ & benzo(a)pyrene & & Assessment \\
\hline \multirow[t]{2}{*}{ CCS } & carbon capture and & MEA & monoethanolamine \\
\hline & sequestration & $\mathrm{MPa}$ & megapascals \\
\hline $\mathrm{CFC}$ & chloroflourocarbon & MWe & megawatt electric \\
\hline CFC-11 & chloroflourocarbon-11; R-11 & MWh & megawatt-hour \\
\hline CFLs & compact fluorescent light bulbs & $\mathrm{N}_{2} \mathrm{O}$ & nitrogen dioxide \\
\hline $\mathrm{CH}_{4}$ & methane & NETL & National Energy Technology \\
\hline $\mathrm{C}_{2} \mathrm{H}_{4}$ & ethene & & Laboratory \\
\hline $\mathrm{CO}_{2}$ & carbon dioxide & NG & natural gas \\
\hline \multirow[t]{2}{*}{ CWRT } & Center for Waste Reduction & $\mathrm{NH}_{3}$ & ammonias \\
\hline & Technologies (of the AIChE) & $\mathrm{NO}_{\mathrm{x}}$ & nitrogen oxides \\
\hline DCB & dichlorobenzen & ODP & ozone depletion potential \\
\hline EBI & Environmental Burden Index & PAH & polycyclic aromatic \\
\hline EP & eutrophication potential & & hydrocarbons \\
\hline \multirow[t]{2}{*}{ EPA } & Environmental Protection & $\mathrm{PC}$ & pulverized coal \\
\hline & Agency & $\mathrm{PM}$ & particulate matter \\
\hline -eq & equivalents & $\mathrm{PO}_{4}^{-3}$ & phosphate \\
\hline \multirow{2}{*}{$\begin{array}{l}\text { ETP } \\
\text { FGD }\end{array}$} & ecotoxicty potential & POFP & photo-oxidant formation \\
\hline & flue gas desulfurization & & potential \\
\hline GHG & greenhouse gases & $\mathrm{Sb}$ & antimony \\
\hline GWP & global warming potential & SCR & selective catalytic reformer \\
\hline $\mathrm{H}_{2} \mathrm{O}$ & water & $\mathrm{SO}_{2}$ & sulfur dioxide \\
\hline $\mathrm{HCFC}$ & hydrochloroflourocarbon & $\mathrm{SO}_{\mathrm{x}}$ & sulfur oxides \\
\hline $\mathrm{HCl}$ & hydrogen chloride & TCOE & total cost of electricity \\
\hline $\mathrm{HF}$ & hydrogen fluoride & TRACI & Tools for Reduction and \\
\hline $\mathrm{Hg}$ & mercury & & Assessment of Chemical and \\
\hline HTP & human toxicity potential & & titar \\
\hline IChemE & Institution of Chemical & $\sqrt{-}$ & ultraviolet-B (medium wa \\
\hline & Engineers & WC & water consumption \\
\hline ICI & Imperial Chemicals, Inc. & & \\
\hline IPCC & $\begin{array}{l}\text { Intergovernmental Panel on } \\
\text { Climate Change }\end{array}$ & & \\
\hline
\end{tabular}





\section{Contents}

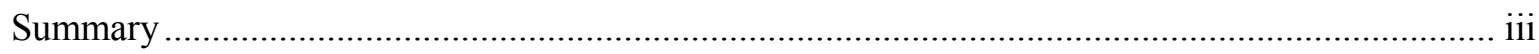

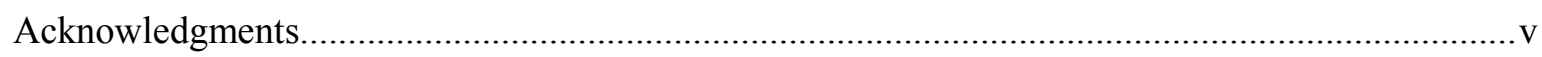

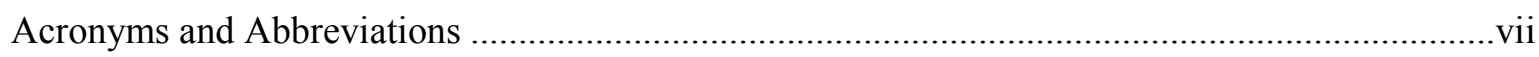

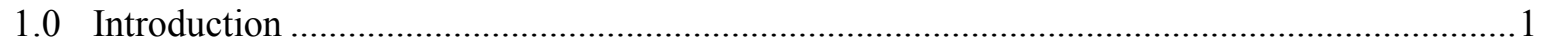

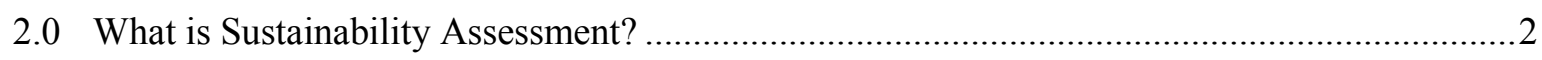

2.1 Use of LCA Methods to Assess Sustainability Impacts of CCS Technologies...................3

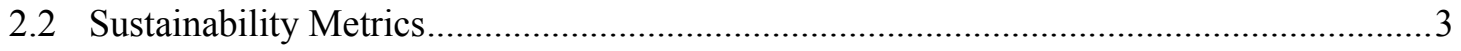

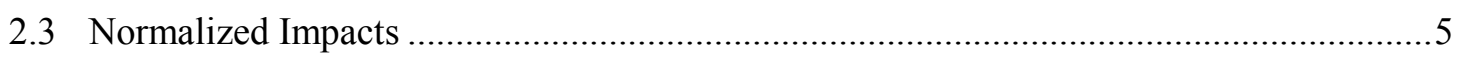

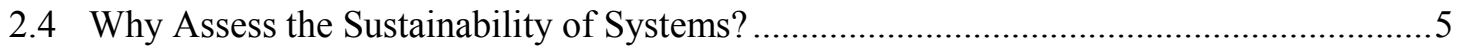

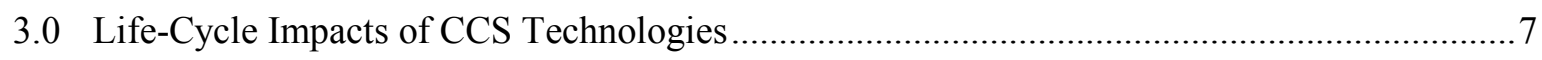

3.1 Technical Assumptions and Design Cases ...............................................................

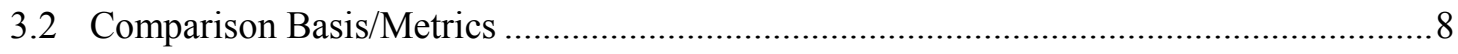

3.3 Relative Impact of Different Processes/Unit Operations ............................................ 10

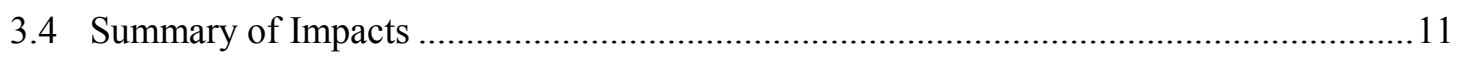

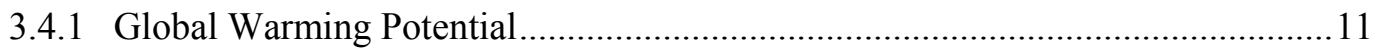

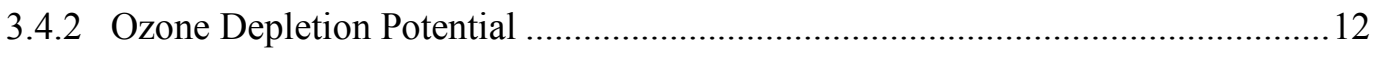

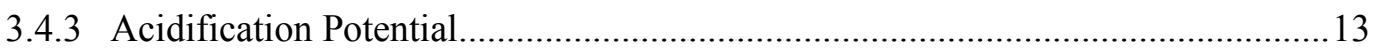

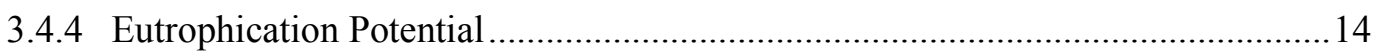

3.4.5 Photo-Oxidant Formation Potential..................................................................... 15

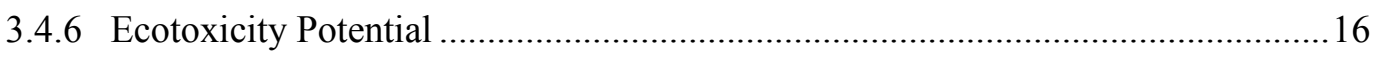

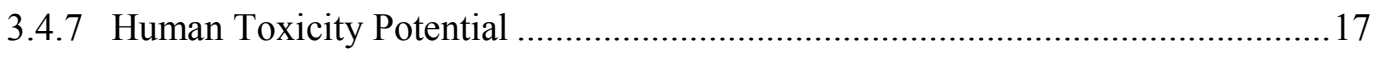

3.4.8 Abiotic Depletion Potential ............................................................................ 19

3.4.9 Water Consumption for Power Production .....................................................2

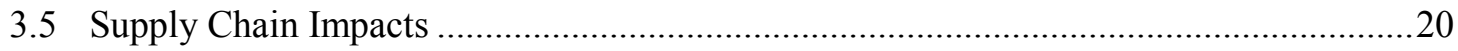

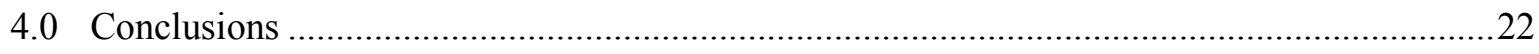

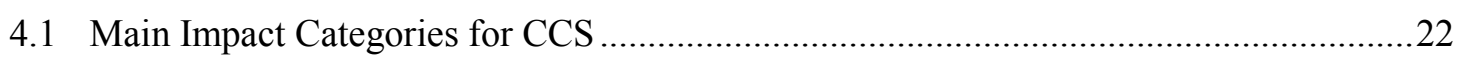

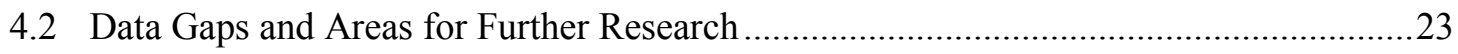

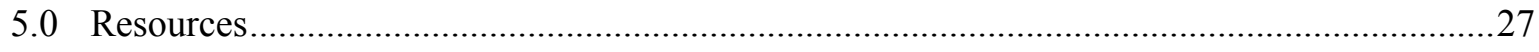




\section{Figures}

Figure 1. Comparison of Global Warming Potential. ................................................................. 11

Figure 2. Comparison of Ozone Depletion Potential.....................................................................12

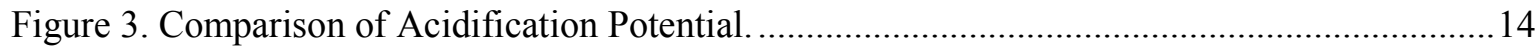

Figure 4. Comparison of Eutrophication Potential .................................................................... 15

Figure 5. Comparison of Photo-oxidant Formation Potential ........................................................ 16

Figure 6. Comparison of Ecotoxicity Potential....................................................................... 17

Figure 7. Comparison of Human Toxicity Potential ................................................................... 18

Figure 8. Comparison of Abiotic Depletion Potential. ................................................................... 19

Figure 9. Comparison of Water Consumption from Power Production.........................................20

\section{Tables}

Table 1. Major Assumptions and Key Parameters Used in this Comparison ..................................7

Table 2. Environmental Impact Categories Considered in the Report...........................................9 


\subsection{Introduction}

As part of a comprehensive review and technical evaluation of various carbon capture and storage (CCS) technologies and strategies, a team of researchers from Pacific Northwest National Laboratory evaluated the expected sustainability impacts of one technology - CCS via monoethanolamine (MEA) stripping - from a full life-cycle perspective. The goal of this assessment was to understand the full lifecycle impacts of CCS, particularly in areas that are not addressed in a traditional techno-economic analysis. The term "sustainability" impacts was chosen deliberately, to reflect a broad array of environmental, resource, economic, and social factors that are often treated as external to the technology. This begs the question of "what is sustainability?" While there are many definitions of sustainability that have been proposed since the definition first put forward by the Brundtland Commission in 1987, we have taken a pragmatic view that considers a sustainability impact to be any impact (typically adverse, but not necessarily) that substantially affects the long-term (multi-generational) viability of a technology (Brundtland, 1987). Thus, this analysis seeks to identify any impacts or issues which affect the long-term and large-scale implementation of CCS technology. An overview of sustainability assessment is provided in Section 2.

This research was done primarily on the basis of previously published, third-party studies and literature reviews to identify what is known regarding the sustainability of coal plants with CCS. A thorough review of the literature for life-cycle analyses of power generation processes using CCS technology via the MEA absorption process, and other energy generation technologies as applicable, yielded large variability in methods and core metrics. This was not unexpected because, life-cycle analysis studies are drawn from multiple sources, have different scopes and goals, and their underlying assumptions tend to complicate the direct comparison or aggregation of data. The data presented in the literature was augmented with some original calculations, for example to normalize units or boundary conditions across disparate studies, but a comprehensive harmonization of these studies was not performed. Also, this study presents only those sustainability metrics addressed in the literature. A thorough assessment of all sustainability impacts was outside the scope of this review, but should be considered in future analyses.

Despite the lack of agreement between the LCA studies analyzed in this literature review, some overarching themes were common between them and key conclusions were distilled from their comparison. A discussion of the technical assumptions and design cases and a summary and comparison of results from the literature is included in Section 3, Life-Cycle Impacts of CCS Technologies. Section 4 presents the key conclusions regarding the main impact categories for CCS and opportunities for future research. 


\subsection{What is Sustainability Assessment?}

There are many policy and business drivers for considering the sustainability impacts of technological systems, but perhaps the most important for technology developers is to anticipate unanticipated technological risks. Public acceptance, commercial viability, regulatory acceptance, or technological interdependence with vulnerable systems are all factors that weigh into the long-term commercial viability of a technology, and each of them can be adversely affected by sustainability impacts that are independent of the technical efficacy of the solution. Examples include poor public acceptance (especially in European Union [EU] nations) of genetically modified organisms; water impacts of enhanced energy recovery technologies, or production bottlenecks and price escalation due to scarcity of strategic materials. These risks are often overlooked in conventional techno-economic analysis, either because they appear to be out of scope of the study or beyond the control of the design team.

The most robust tool to assess the sustainability impacts of a technology or system is life-cycle assessment or analysis (LCA). Life-cycle analysis is a framework that allows for the systematic assessment of a system or technology's impacts on the environment, human health, and resources through a full cycle of use, from raw material extraction to end-of-life management and disposal (Bare et al. 2003; Manuilova et al. 2009). This often includes the supply chain of products required for manufacture or production; for example, the environmental impact of steel production will be a consideration in the LCA of coal plants because of the steel used in plant construction. Life-cycle analyses use existing data sets to analyze material and energy flows and assign environmental impacts to all those materials flows. The method of conducting LCA is defined according to internationally recognized International Organization of Standardization (ISO) 14040 standards. According to ISO 14044 (2006), there are four phases of a LCA:

1. Goal and scope definition, where the intent of the LCA, the scope boundaries, and the functional unit is defined

2. Inventory analysis, where data for all processes and material and energy flows is gathered and organized

3. Impact assessment, where the LCA inputs are translated into environmental outputs that provide information on a system's impacts

4. Interpretation of results, where the results of the LCA are evaluated according to the studies goals. This step can include comparison of several scenarios or sensitivity analysis..

While an LCA can be very comprehensive in scope and depth, it addresses primarily environmental impacts. Other impacts that are important to consider to truly determine the sustainability of a system or technology are economic viability, regulatory or public policy hurdles, supply chain issues, and other potentially technology-specific impediments to growth and sustainability. In-depth consideration of all of these impact areas is outside the scope of this short literature summary, and none of the published studies that we identified addressed these issues in any meaningful manner (although supply chain issues are addressed briefly based on our own analysis in Section 2.5). This report serves to define the existing literature related to the sustainability impacts of a coal plant with CSS. 


\subsection{Use of LCA Methods to Assess Sustainability Impacts of CCS Technologies}

Since the $1950 \mathrm{~s}$, carbon dioxide $\left(\mathrm{CO}_{2}\right)$ emissions from human activity have increased dramatically. This has been linked to increasing ambient $\mathrm{CO}_{2}$ concentrations in the atmosphere (IPCC 2007). In 1996, the Intergovernmental Panel on Climate Change (IPCC) described some of the negative impacts of increased atmospheric $\mathrm{CO}_{2}$ concentrations, including global mean temperature rise, increase in ocean levels, and stronger tropical storms. These impacts are collectively referred to as climate change. Carbon dioxide emissions from the combustion of fossil fuels are the largest contributor to greenhouse gas (GHG) emissions in the United States (EPA 2010). Application of CCS on new and existing power plants has the ability to dramatically reduce $\mathrm{CO}_{2}$ emissions from power production. Odeh and Cockerill (2008) find the potential for 75-84 percent reductions in $\mathrm{CO}_{2}$ emissions on a life-cycle basis, depending on the technology, which is consistent with other studies (Zhang et al. 2009; Marx et al. 2011; Singh et al. 2011). As such, utilities and policymakers are considering the wide-spread implementation of CCS technology on new and existing coal plants to dramatically curb GHG emissions from the power-generation sector.

However, the implementation of CCS systems will have many other social, economic, and environmental impacts beyond curbing GHG emissions that must be considered to achieve sustainable energy generation. For example, emissions of nitrogen oxides $\left(\mathrm{NO}_{\mathrm{x}}\right)$, sulfur oxides $\left(\mathrm{SO}_{\mathrm{x}}\right)$, and particulate matter (PM) are also important environmental concerns for coal-fired power plants. If the parasitic energy consumption of a carbon-capture plant increases the emissions of one of these other air pollutants, the technology should not be viewed as sustainable or environmentally friendly. In fact, some of these "external" or "tangential" impacts may prove to be equally important and prevent the successful and sustainable implementation of CCS technology on a large scale. For example, several studies have shown that eutrophication is expected to double (Odeh and Cockerill 2008) and acidification would increase due, in part, to increases in $\mathrm{NO}_{\mathrm{x}}$ emissions from power production and ammonia $\left(\mathrm{NH}_{3}\right)$ emissions from MEA manufacture (Pehnt and Henkel 2009). Human toxicity, which is an indicator of emissions of substances that have the potential to impact human health, is also expected to increase due to increased heavy metals in water from increased coal mining and MEA hazardous waste (Korre et al, 2010).

\subsection{Sustainability Metrics}

The iconic definition of sustainability derives from the Brundtland Commission's 1987 report on Sustainable Development, entitled Our Common Future (Brundtland, 1987). From that document, sustainability is defined as "[activities that]....meet the needs of the present without compromising the ability of future generations to meet their needs." Despite the difficulty of making such a broad definition operational and actionable, it has persisted for nearly a quarter century because of its simplicity.

Nonetheless, the persistence of the Brundtland definition has not stopped an entire generation of researchers, pundits, and consultants from putting forward new definitions or developing more practical ways of measuring progress towards that vision. Most of these efforts were motivated by the adage "what gets measured, gets managed" and sought to develop metrics that could be used to evaluate progress towards more sustainable business operations at the process, business unit, or corporate level.

A full discussion of sustainability metrics is beyond the scope of this document. However, it is useful to note that accepted ideas of what represents appropriate sustainability metrics have evolved significantly 
since the early 1990s. Most of the early frameworks, including the Environmental Burden Index (EBI) developed by Imperial Chemicals, Inc. (ICI; Wright et al. 1997), were focused on direct environmental impacts resulting from emissions to the environment. In recent years, much more comprehensive frameworks have been proposed, including the Center for Waste Reduction Technologies (CWRT) of the American Institute of Chemical Engineers (AIChE) sustainability metrics (Schwartz et al. 2002), which added a dimension of business sustainability by normalizing environmental impact to production; and the Institution of Chemical Engineers (IChemE) metrics (IChemE 2002), which can be seen as a synthesis of the ICI burden approach and the CWRT metrics. For instance, the IChemE metrics borrow the concept of the ICI burden index, but merge it with the normalization against economic activity, resulting in a "burden per dollar value added." The IChemE sustainability framework also added social aspects of sustainability, a significant step towards recognizing that component of sustainability.

This trend towards more and more comprehensive sets of sustainability metrics resulted in measurement frameworks that were certainly more robust in terms of what they measured-but also significantly more burdensome in terms of data collection requirements. Perhaps as a consequence of this evolution, more and more "application specific" sustainability metrics have emerged over the past 10 years. These often focus on a product or set of product categories or on an industry sector. Although arguably not as comprehensive as the broadly scoped sustainability metrics provided by the IChemE framework, they serve a useful purpose in focusing attention on sustainability measurement in sectors where comparisons between emerging technologies are important, or where industry certification to a standard is expected.

The recent trend has been to establish more site-dependent LCA tools. These tools relay on metrics and characterization factors that are specific for a certain country or region. Examples of this are the European IMPACT 2002+, the Japanese LIME, and the Canadian LUCAS (Manuilova 2009; Toffoletto et al. 2007). LCA tools or models that could be applicable to the United States are the Life-Cycle Stressor-Effect Assessment (LCSEA) developed by Scientific Certification Systems (2011) and Tool for the Reduction and Assessment of Chemical and other environmental Impacts (TRACI) developed by the U.S. Environmental Protection Agency (EPA; Bare et al. 2003).

For the purposes of this investigation, we elected to focus on a set of sustainability metrics that has been popularized by the EPA's TRACI framework (Bare et al. 2003). TRACI was chosen because it is a wide-ranging set of environmental metrics, elements of the framework are commonly reported in the LCA literature, and because of its U.S.-based focus (Manuilova et al. 2009).

TRACI covering the following environmental impact categories:

- ozone depletion

- global warming

- acidification

- eutrophication

- tropospheric ozone (smog) formation

- ecotoxicity

- human particulate effects 
- human carcinogenic effects

- human non-carcinogenic effects

- fossil-fuel depletion

- land-use effects.

These categories are described in more detail in Table 2, in Section 2.2.

\subsection{Normalized Impacts}

While these environmental indicators explain a significant amount about the individual impacts, even those relative changes in environmental impact must have context in order for the data to be interpret effectively. It is also important to consider the individual and incremental increases in impact categories relative to total impact in an area. For example, when compared to world or U.S. total GHG emissions, how much are you decreasing GHG emissions relative to how many metric tonnes of $\mathrm{CO}_{2}$-eq the United States or world emits annually?

There are methods to normalize these impacts further to a single metric, such as total cost of electricity (TCOE) or some sort of "sustainability score." However, which of these indicators is more important than another is a very subjective matter. Furthermore, once rolled up into a single number or cost impact, the individual impacts are lost. While one metric may seem to make it easier to compare technologies on a uniform basis, it actually makes it very difficult to determine the cause of differences between technologies. In this case, it seems most appropriate to keep the indicators as they are. Then, policymakers and other entities can make their own decisions about weighting factors that are most appropriate for a specific situation.

\subsection{Why Assess the Sustainability of Systems?}

From a broad public policy perspective, understanding the life-cycle sustainability impacts of CCS technology is an important undertaking on its own merits. Sustainability - meeting the needs of the current generation while not impeding future generations to meet their own needs - is a policy imperative at the federal level and increasingly a paradigm espoused by the private sector. But why do these impacts matter from an engineering perspective that is primarily focused on reducing the cost of energy?

The simple answer is that these costs affect the total cost of energy in a variety of ways, primarily through the superposition of externalized costs. Externalized costs are costs borne by someone other than the business that generates the costs (often, externalized costs are passed on to society as a whole). As an example, the environmental impact of $\mathrm{CO}_{2}$ emitted from a power plant is expected to contribute, incrementally, to higher costs for dealing with the consequences of climate change; under current economic and regulatory frameworks, these costs are typically not borne by the power plant but by society as a whole.

Should externalized costs be included in the total cost of energy? The answer of course hinges upon how the TCOE figures will be used. However, the trend in business is increasingly to recognize and account for externalized costs where possible, because many of these costs have a way of "coming back 
to roost." The following are some common ways that externalized costs can increase the operational costs of an enterprise:

- Regulation. Costs that are routinely externalized may be redistributed through policy or regulation; for example, concerns about the effects of mercury in the environment have led the EPA to place strict limits on the amount of mercury that can be emitted from power plants and other processing facilities. These limits impose new costs for control technologies or fundamental process changes that avoid the emissions in the first place. While current regulatory costs are generally factored into the TCOE, costs of potential future regulations are not - even though they may have a very real (if uncertain) impact on the TCOE.

- Contingent/catastrophic costs. Some costs are externalized in the sense that they only occur in the event of an unplanned or catastrophic event. The costs of dealing with a major oil spill, for example, are contingent costs that are arguably reflected in insurance rates. A more careful accounting of the risks associated with transporting the oil might assign a portion of the insurance cost to the total cost of using oil as an energy resource.

- Social license to operate. A final "cost" associated with sustainability impacts is one that is well recognized within the chemical manufacturing industry, and indeed has motivated the industry's early adoption of sustainability metrics: the social license to operate. The willingness of society to accept the environmental and other risks associated with a particular technology is often reflected in the resistance that stakeholder groups can muster to siting new facilities or acceptance of new products in the marketplace. This resistance is often reflected in higher costs and longer delays for permitting new facilities or facility upgrades.

An important feature to note about all of these costs is the relatively high degree of uncertainty and/or stochastic nature of each of them. Specifically, many of these costs are more representative of an individual's or an organization's values, rather than true monetary costs. As such, the actual weighting and consideration of a variety of LCA impacts as an overall sustainability "score" requires further input from policy- and decision-makers. 


\subsection{Life-Cycle Impacts of CCS Technologies}

To assess the externalized environmental, social, and economic impacts of CCS technology, the research team conducted a review of the published literature for LCAs and related studies of coal plants, with and without CCS, and natural gas plants, with and without CCS. Literature data were compared and combined to characterize four primary design cases: 1) supercritical pulverized coal (PC) power plant without CCS (PC w/o CCS), 2) PC power plant with CCS where the additional energy requirements come from a similar PC coal plant with CCS (PC with CCS), 3) PC power plant with CCS where the additional energy requirements come from a natural gas (NG) plant without CCS (PC with CCS \& NG), and 4) PC power plant with CSS where the additional energy requirements come from a NG plant with CCS (PC with CSS \& NG with CCS). The technical assumptions, design cases, and metrics used in this analysis, and the contribution of different component processes to the overall life-cycle impact category are presented in the following sections. These design cases are compared on a variety of environmental impact metrics, as described by the EPA's TRACI framework (Bare et al. 2003). The weighting of these environmental impact metrics is also discussed.

\subsection{Technical Assumptions and Design Cases}

The assumptions made in these studies with regard to the type of coal, transport distance, details of the reference plant design, and method of $\mathrm{CO}_{2}$ storage strongly affect the results. In fact, Korre et al. (2010) find that coal type is the dominant factor in determining the environmental impact of coal-fired power production with CCS. Some of the studies included in this analysis use lignite coal in their models, which has the highest global warming potential, due to its low heating value, but lower photooxidant formation potential and acidification than other coals due to its low sulfur content. Other studies used hard coal (Viebahn et al. 2007; Pehnt and Henkel 2009), but many did not specify a coal type (Zhang et al. 2009). This makes normalization of the data based on coal type difficult. For this analysis, the environmental impacts of a 500-megawatt electric (MWe) supercritical PC power plant with modern air emission control technologies (PC w/o CCS) will be compared to 1) a 500-MWe PC coal plant with CCS where the additional energy requirements come from a similar PC coal plant with CCS (PC with CCS), 2) a PC coal plant with CCS where the additional energy requirements come from a NG plant without CCS (PC with CCS \& NG), and 3) a PC coal plant with CSS where the additional energy requirements come from a NG plant with CCS (PC with CSS \& NG with CCS). In all cases, carbon capture is assumed to be provided by an amine-stripping system using MEA as the sorbent. Most studies find an energy penalty due to CCS of 30 percent (Sathre 2001). However, this varies based on the coal type and specific plant design. This study assumes a value of 30 percent. All captured $\mathrm{CO}_{2}$ is compressed and transported to a sequestration well. The range of transportation pressures and distances vary from 10.7 to 15 megapascals (MPa) and 50 to 300 kilometers (Nie et al. 2011; Koornneef 2008; Zhang et al. 2009). The $\mathrm{CO}_{2}$ is assumed to be sequestered in an underground aquifer forever with no leakage. Table 1 lists the major assumptions used for this analysis and used in the majority of studies.

Table 1. Major Assumptions and Key Parameters Used in this Comparison

Parameter Value




\begin{tabular}{ll}
\hline Size of Plant & $500 \mathrm{MWe}$ \\
Type of Coal & Lignite \\
$\mathrm{CO}_{2}$ Sequestration System & MEA \\
$\mathrm{CO}_{2}$ Capture Efficiency & $90 \%$ \\
Percentage Increase in Resource & $30 \%$ \\
Use Due to CCS & \\
\hline
\end{tabular}

The functional unit of comparison is one $1 \mathrm{MWh}$ electricity delivered to the grid. While the system boundary for all of the studies is comprehensive in scope-from extraction and production of raw materials to final disposal - certain component processes may have been ignored or left out in some cases. This is often because the process is deemed to not significantly affect the LCA result. However, which processes have been analyzed and to what extent is not consistent in all studies. For example, some studies included plant construction impacts and raw material supply chains, while others did not (Zhang et al. 2009). Zhang et al. (2009) and Marx et al. (2011) present good summaries of the LCAs performed on coal plants with CCS to date. In this review, all life-cycle stages are considered, including raw material extraction, transportation, plant construction, power production, waste disposal, plant decommissioning, and $\mathrm{CO}_{2}$ transmission and sequestration.

\subsection{Comparison Basis/Metrics}

A number of LCAs performed compare the technologies based on GHG emissions (Spath and Mann. 2004), and a few others include other impact categories such as criteria emissions, acidification, eutrophication, and toxicity (Zhang et al. 2009; Tzimas et al. 2007; Rao and Rubin 2002; Koornneef 2008). The most detailed reports, such as those conducted by the National Energy Technology Laboratory (NETL; Black 2010) and the EPA (Nexant 2006), expanded on process models for technoeconomic analysis, presenting the raw $\mathrm{CO}_{2}, \mathrm{NO}_{\mathrm{x}}, \mathrm{SO}_{\mathrm{x}}$, and $\mathrm{PM}$ emissions, as well as emissions of heavy metals, like mercury (Hg) (Black 2010; Nexant 2006). These reports also focused on emissions within the plant boundary and did not account for upstream or downstream impacts. Published literature has expanded on these types of studies to present emissions from the complete life cycle of power plants with CCS (Koornneef 2008; Pehnt and Henkel 2009; Zhang et al.; Singh et al. 2011).

To give this raw emissions data context, it is important to understand the relative environmental impacts of these materials flows. For example, installing CCS on a PC coal plant could double the emissions of methane associated with coal extraction, due to the increased coal consumption, but will decrease the $\mathrm{CO}_{2}$ emissions associated with combustion. Both methane and $\mathrm{CO}_{2}$ are GHGs that contribute to climate change. However, methane has more ability to warm the atmosphere, per gram, than $\mathrm{CO}_{2}$. Thus, to compare relative flows, these two streams must be converted into equivalent units. In this case, methane emissions are converted into $\mathrm{CO}_{2}$-equivalent units to describe the "global warming potential" of each flow. Doing this allows the two streams' impact on global warming to be compared to determine if, overall, the process has a negative or positive impact on global warming potential and the relative size of that change. In the case of a PC coal plant with CCS, the reduction in combustion emissions far outweighs the increase in methane emissions, and the result is a significant net decrease in global warming potential over the PC coal plant baseline. This same methodology can be applied to many material flows and other impact categories.

Many different systems of metrics or indicators have been defined to describe sustainability impacts, as discussed in Section 2.2. In this report, materials flows are described in terms of environmental impact 
indicators defined in the EPA's TRACI model, because these are the values that are most represented in the literature (Bare et al. 2003). Because TRACI has been used extensively in the reporting of LCA results in the peer-reviewed literature, we focused our evaluation primarily on a subset of these metrics, choosing to bin the three human health categories (particulate, carcinogenic, and non-carcinogenic effects) into a single category of "human toxicity."

We also used the somewhat broader concept of abiotic resource depletion in lieu of fossil-fuel depletion, because it is more encompassing and more often reported in the literature. Two impact categories that we have included, but are not part of the original TRACI framework, are water consumption $^{1}$ and supply chain vulnerability.

The TRACI indicators interpret the individual mass and energy flows in each stage of the life cycle and each process to be associated with the propensity for that specific mass or energy to affect the environment and in what capacity. This allows many different emissions and materials flows to be analyzed together and provides a method for meaningful interpretation of their relative impact. Examples of indicators include acidification potential, eutrophication potential, and human toxicity potential. In addition to the indicators described in TRACI, water consumption and supply chain impacts were also analyzed. The indicators compared in this literature review, a description of the indicator, the emissions that contribute to that indicator, and the characterization factor are listed in Table 2.

Table 2. Environmental Impact Categories Considered in the Report

\begin{tabular}{|c|c|c|c|c|}
\hline Indicator & Abbr. & Summary & Relevant Emissions & $\begin{array}{l}\text { Characterization } \\
\text { Factor }\end{array}$ \\
\hline $\begin{array}{l}\text { Global } \\
\text { Warming } \\
\text { Potential }\end{array}$ & GWP & $\begin{array}{l}\text { Impact of anthropogenic emissions which } \\
\text { enhance the radiative forcing of the } \\
\text { atmosphere. }\end{array}$ & $\begin{array}{l}\mathrm{CO}_{2}, \mathrm{CH}_{4}, \mathrm{~N}_{2} \mathrm{O} \\
\text { halocarbons }\end{array}$ & $\mathrm{kg} \mathrm{CO}$-eq/MWh \\
\hline $\begin{array}{l}\text { Ozone } \\
\text { Depletion } \\
\text { Potential }\end{array}$ & ODP & $\begin{array}{l}\text { Impact on stratospheric ozone layer due } \\
\text { to anthropogenic emissions, which causes } \\
\text { a greater level of UV-B radiation to reach } \\
\text { the earth's surface }\end{array}$ & $\begin{array}{l}\text { CFCs, HCFCs, halons, } \\
\text { methyl bromide }\end{array}$ & $\begin{array}{l}\mathrm{kg} \mathrm{CFC11-} \\
\mathrm{eq} / \mathrm{MWh}\end{array}$ \\
\hline $\begin{array}{l}\text { Acidification } \\
\text { Potential }\end{array}$ & AP & $\begin{array}{l}\text { Impact of acidifying pollutants on soil, } \\
\text { groundwater, surface waters, and } \\
\text { ecosystems. }\end{array}$ & $\begin{array}{l}\mathrm{SO}_{x}, \mathrm{NO}_{x}, \mathrm{HCl}, \mathrm{HF}, \\
\mathrm{NH}_{3}\end{array}$ & $\mathrm{~kg} \mathrm{SO}_{2}$-eq/MWh \\
\hline $\begin{array}{l}\text { Eutrophication } \\
\text { Potential }\end{array}$ & EP & $\begin{array}{l}\text { Impact of excessive macronutrients in } \\
\text { terrestrial and marine ecosystems }\end{array}$ & $\begin{array}{l}\mathrm{PO}_{4}, \mathrm{NO}_{x}, \text { nitrates, } \\
\mathrm{NH}_{3}\end{array}$ & $\mathrm{~kg} \mathrm{PO}_{4}^{-3}-\mathrm{eq} / \mathrm{MWh}$ \\
\hline $\begin{array}{l}\text { Photo-oxidant } \\
\text { Formation } \\
\text { Potential }\end{array}$ & POFP & $\begin{array}{l}\text { Propensity to produce certain air } \\
\text { pollutants which react with sunlight to } \\
\text { form reactive chemical compounds, such } \\
\text { as ozone, which negatively impact on the } \\
\text { terrestrial ecosystem }\end{array}$ & $\begin{array}{l}\text { Non-methane- } \\
\text { hydrocarbon. Note: } \\
\text { most LCAs do not } \\
\text { account for impact of } \\
\mathrm{NO}_{\mathrm{x}} \text { on ozone forming } \\
\text { reactions }\end{array}$ & $\mathrm{kg} \mathrm{C}_{2} \mathrm{H}_{4}-\mathrm{eq} / \mathrm{MWh}$ \\
\hline $\begin{array}{l}\text { Ecotoxicity } \\
\text { Potential }\end{array}$ & ETP & $\begin{array}{l}\text { Impacts of toxic substances on aquatic } \\
\text { and terrestrial ecosystems }\end{array}$ & $\begin{array}{l}\text { Mercury, chromium, } \\
\text { cadmium, dioxins, } \\
\text { arsenic, other toxic } \\
\text { compounds }\end{array}$ & kg DCB-eq/MWh \\
\hline $\begin{array}{l}\text { Human } \\
\text { Toxicity }\end{array}$ & HTP & $\begin{array}{l}\text { Impacts of toxic substances on human } \\
\text { health }\end{array}$ & $\begin{array}{l}\mathrm{PM}_{10}, \mathrm{PM}_{2.5}, \text { soot, } \\
\mathrm{XO}_{2}, \mathrm{NO}_{\mathrm{x}}, \mathrm{CH}_{4}\end{array}$ & kg DCB-eq/MWh \\
\hline
\end{tabular}

${ }^{1}$ TRACI addresses one form of water resource depletion — eutrophication — but does not explicitly deal with other forms of consumptive or non-consumptive water quality impacts. 
Potential

Abiotic

Resource

Depletion

Potential

Water

Consumption
ADP

Depletion of natural resources (including energy resources)

Water consumed in the production of power, primarily cooling tower losses. Note, this is from the NETL Baseline report and does not include life-cycle impacts outside the plant gate. formaldehyde, benzene, B(a)P, PAH, arsenic, cadmium, dioxin, furan, other toxic compounds

Mineral use, fossil-fuel use, etc.

kg Sb-eq/MWh

kgal $\mathrm{H}_{2} \mathrm{O} / \mathrm{MWh}$

\subsection{Relative Impact of Different Processes/Unit Operations}

Another important aspect of sustainability assessment is to compare the impact of different component processes. This can help determine primary contributors to the overall environmental impact in each category and define key opportunities for improvement. Therefore, the relative impact of each major component process will also be portrayed in the results. These major component processes are listed and described below:

- Coal Mining and Transportation. Mining and transportation of coal to the boiler, including pulverizing the coal. This also includes the coal plant construction impacts.

- Natural Gas Production and Transportation. Production and transportation of natural gas. This does not include combustion of natural gas; it is included under Power Production.

- MEA Production and Disposal. Production and disposal of MEA. This does not include additional coal requirements.

- Other Emissions Control Technologies. Combined impacts of sulfur dioxide $\left(\mathrm{SO}_{2}\right), \mathrm{NO}_{\mathrm{x}}$, and particulate removal technologies, including production of raw materials to disposal of waste streams. There is significantly reduced confidence in the estimated contributions from these processes due to the lack of specific data.

- Power Production. Combustion of coal in the boiler, resulting air emissions and waste generation

- Sequestration. $\mathrm{CO}_{2}$ transportation and storage. Studies typically assume sequestration strategies do not leak or fail.

While some papers present information regarding the contribution of different component processes, in general data are lacking. Specifically, there are limited data on the contribution of the individual contribution of other emissions control technologies or the specific impact of parasitic power consumption. Thus, the relative contributions of each process presented in the results are illustrative in terms of indicating relative magnitudes of impact. 


\subsection{Summary of Impacts}

The results of this literature review serve to both characterize relative impacts in a number of different environmental impact categories and define the state of knowledge regarding the sustainability impacts of PC coal plants with a variety of MEA-based CCS systems. These results indicate key impact areas and opportunities for improving the sustainability of PC plants with CCS, as well as identify data gaps and areas for further research. The following sections summarize the sustainability impacts in each indicator category for the PC coal plant, PC coal plant with CCS, PC coal plant with CCS \& NG, and PC coal plant with CCS \& NG with CCS. The contribution of each process - coal mining and transportation, natural gas production and transportation, MEA manufacture and disposal, other emissions controls technologies, power production, and sequestration - is identified. The range of values found in the literature is represented as well.

\subsubsection{Global Warming Potential}

Global warming potential (GWP) represents the impact of anthropogenic emissions that enhance the radiative forcing of the atmosphere (Bare et al. 2003; Pehnt and Henkel 2009; Lippiatt 2007; Korre 2010). As expected, GWP is seen to decrease dramatically in all studies as a result of CCS. Most studies find a reduction of 68 to 81 percent with CCS over the base case for PC (Zhang et al. 2009; Sathre. 2011). The majority of these emissions in the base case, PC without CCS, come from power production, as can be seen in Figure 1. Coal mining is also a significant contributor, composing approximately 10 percent of GWP in the base case. About half of the contribution from coal mining and transportation is due to methane emissions (Korre et al. 2010). The total GWP contribution from coal mining and transportation increases for a coal plant with CCS due to increased coal consumption required to maintain 500-MWe power production. The GWP increased slightly when parasitic power is assumed to be supplied by a NG plant without CCS due to methane releases during raw material extraction, production, and transportation (Tzimas et al. 2007).

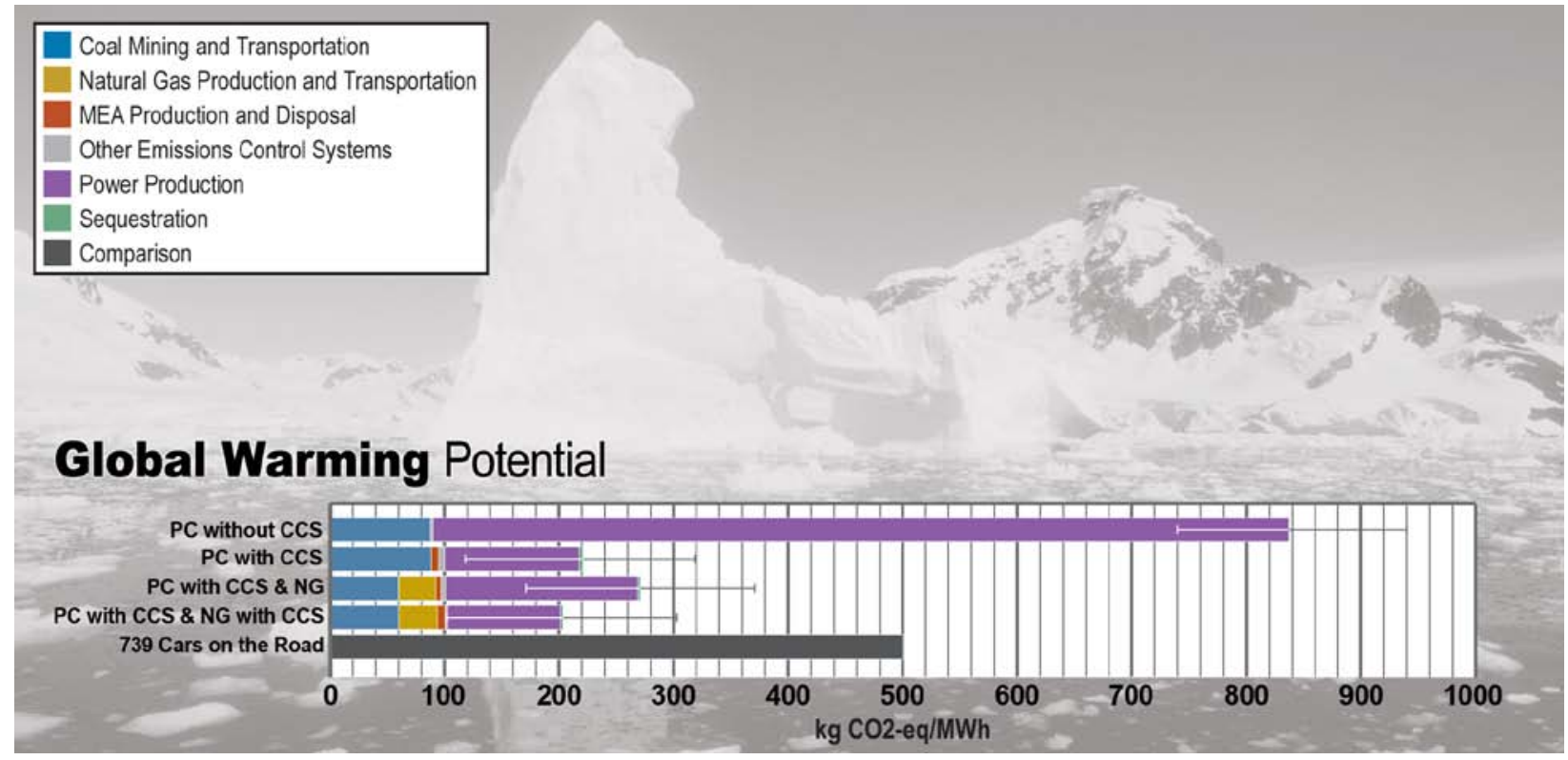

Figure 1. Comparison of Global Warming Potential. Black lines represent the range of values found in the literature. Emissions related to driving a car is given in units of $\mathrm{kg} \mathrm{CO}_{2}-\mathrm{eq} / \mathrm{hr}$. 
For a NG plant without CCS, about 26 percent of the overall GWP is attributed to gas production and transport, compared to only 6 to 10 percent for a PC plant (Odeh and Cockerill 2008). Natural gas with CCS reduces GHG emissions by 65 percent compared to a NG plant without CCS (Viebahn et al. 2007). Assuming the parasitic power required to maintain $500 \mathrm{MWe}$ comes from a NG plant that is also equipped with CCS provides the most dramatic decrease in GWP. The contribution from coal and natural gas production and transportation to overall GWP is highest in this case due to the increased fuel requirements. In all cases, the contribution to total GWP from other systems is negligible. However, it should be noted that this assumes no leakage of the sequestration system.

This is a significant reduction in GWP because coal plants contribute about 27 percent to total U.S. GHG emissions annually (EPA 2011). Implementing CCS on all coal plants could reduce U.S GHG emissions by approximately 15 percent (Lippiatt, 2007). To give the magnitude of GHG emissions context, the annualized reduction in GWP between the coal plant with and without CCS is the same as taking 739 cars off the road (EPA 2000).

\subsubsection{Ozone Depletion Potential}

Ozone depletion potential (ODP) represents the impact on the stratospheric ozone layer due to anthropogenic emissions, which causes a greater level of ultraviolet-B (UV-B) radiation to reach the earth's surface (Bare et al. 2003; Lippiatt 2007). Chemical emissions that contribute to ODP include chloroflourocarbons (CFCs), hydrochloroflourocarbons (HCFCs), halons, and methyl bromide. Implementing CCS on coal-fired power plants does not dramatically affect ODP. As shown in Figure 2, construction impacts are the most significant in this category, primarily due to increased use of crude oil related to coal mining and transportation (Koornneef et al. 2008). Paints and solvents used on construction of the coal plant, $\mathrm{CO}_{2}$ pipeline, and other infrastructure were also found to play a small role (Nie et al. 2011).

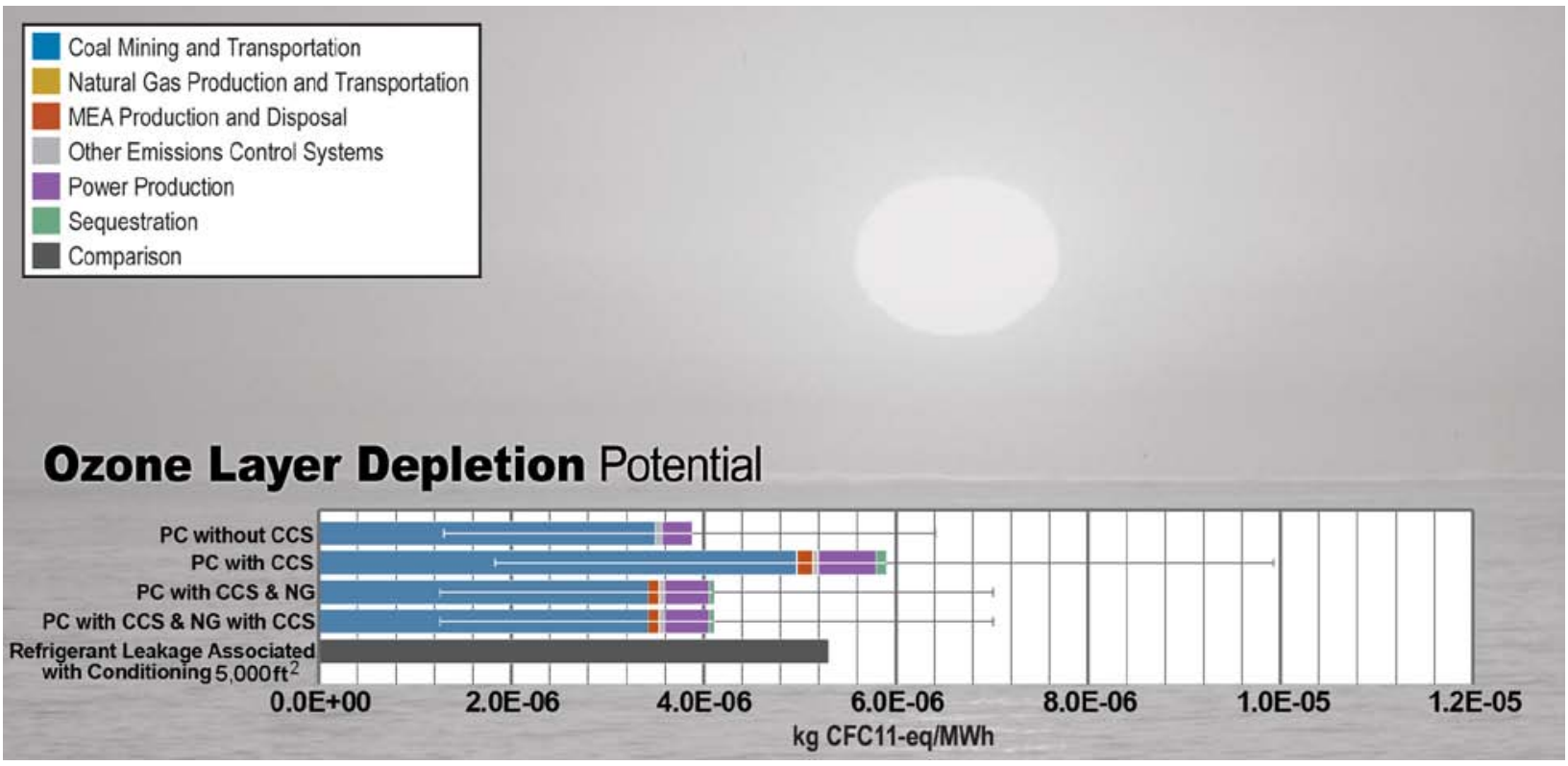

Figure 2. Comparison of Ozone Depletion Potential. Black lines represent the range of values found in the literature. Refrigerant leakage associated with conditioning $5,000 \mathrm{ft}^{2}$ in units of $\mathrm{kg} \mathrm{CFC}$ $11-\mathrm{eq} / \mathrm{hr}$. 
Impacts are decreased for NG plants because primarily due to lack of data. Although, ODP was not found to change considerably between the NG plant without CCS and NG plant with CCS because NO is the dominant contributor for this category (Veltman et al. 2010).

The overall increase in ODP is very small. The contribution per megawatt-hour (MWh) to ODP from one $500 \mathrm{MW}$ coal plant with CCS is approximately equal to the hourly refrigerant leakage associated with conditioning a $5,000 \mathrm{ft}^{2}$ office building.

\subsubsection{Acidification Potential}

Acidification potential (AP) represents the impact of acidifying pollutants on soil, groundwater, surface waters, and ecosystems (Bare et al. 2003; Lippiatt2007; Pehnt and Henkel 2009). Most studies found that the addition of CCS increased acidification slightly due to increased $\mathrm{NO}_{\mathrm{x}}$ and $\mathrm{NH}_{3}$ emissions from the selective catalytic reformer (SCR) and MEA degradation (Odeh and Cockerill 2007; Singh et al., 2011; Sathre 2011). Viebahn et al. (2007) found that AP would increase 38 percent. While the overall AP increased slightly, $\mathrm{SO}_{\mathrm{x}}$ and other acid $(\mathrm{HCl})$ gas emissions decreased due to reaction with the solvent and sulfur polishing upstream of the MEA (Zhang et al. 2009). Some studies did not account for $\mathrm{NO}_{\mathrm{x}}$ and $\mathrm{SO}_{\mathrm{x}}$ uptake in the solvent, which would further reduce emissions in those cases (Tzimas et al. 2007). Also, assumptions about coal transportation affected the contribution from coal mining and transportation, with one study finding coal transportation contributing 80 percent to overall acidification due to the use of sulfur-containing diesel fuel for ship transport (Koornneef et al. 2008).

Figure 3 shows that a large portion the increase in AP is associated with MEA production and disposal. The large change in the relative contribution from coal mining and transportation from the PC without CCS case compared to all the other cases is due to differences in the number of studies considered and the range of values from the those studies. Specifically, many more studies presented acidification information for PC power plants with CCS than the baseline PC power plant without CCS case. Differences in attribution of some impact categories changed how the emissions were allocated to different processes or life-cycle stages. However, the specific differences were not presented in the studies and could not be normalized. Thus, higher estimates of the impact due to coal mining and transportation increased the average for the PC with CCS case. 


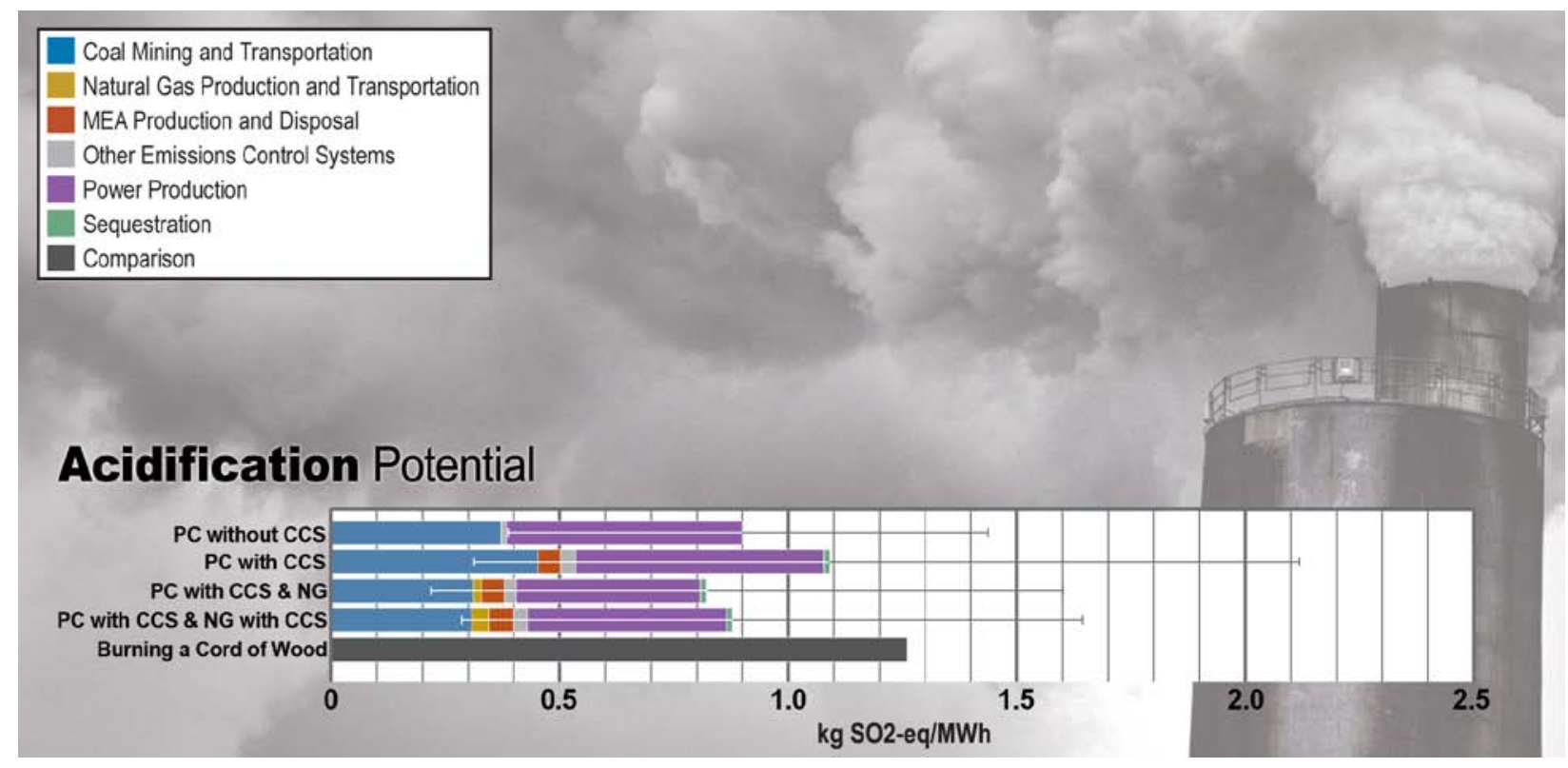

Figure 3. Comparison of Acidification Potential. Black lines represent the range of values found in the literature. Burning of a cord of wood is given in units of $\mathrm{kg} \mathrm{SO}_{2}$-eq.

The AP of a PC plant with CCS and NG decreases significantly due to decreased sulfur and flue gas desulfurization (FGD) emissions (Tzimas et al. 2007). The impact of a PC plant with CCS and NG with CCS increases relative to the PC plant with CCS and NG, but is still lower than both PC plant cases. The increase in AP for the PC plant with CCS and NG with CCS is a result of increased emissions in the production and transportation of $\mathrm{NG}$, as well as increased $\mathrm{NO}_{\mathrm{x}}$ emissions from power production due to the increase in fossil energy requirements (Koornneef et al. 2008).

The change in AP is somewhat uncertain due to differing conclusions of the studies, but is generally shown to increase slightly, although this change is small. While the increase in AP is not as significant as other categories, coal-fired power plants contribute about 3 percent to overall world acidification. Thus, the addition of CCS to coal-fired power plants could increase the total acidification impact by about 1 percent (Marx et al. 2011). To put this level of acidification in context, the AP of all cases analyzed, per $\mathrm{MWh}$, is similar to the AP and $\mathrm{NO}_{\mathrm{x}}$ emissions associated with burning a cord of wood.

\subsubsection{Eutrophication Potential}

Eutrophication potential (EP) is the excessive supply of nutrients to surface water bodies and soils (Bare et al. 2003; Lippiatt 2007; Pehnt and Henkel 2009). Most studies find CCS increases eutrophication due to increased emissions of $\mathrm{NO}_{\mathrm{x}}$ and $\mathrm{NH}_{3}$ emissions from SCR slip and MEA degradation (Odeh and Cockerill 2007; Pehnt and Henkel 2009). Viebahn et al. (2007) estimated that EP would increase 44 percent for the PC with CCS case compared to the PC without CCS case (Viebahn et al 2007). Another study shows a 136 percent increase, but finds it is due to increased emissions of phosphorus and phosphate to water from the disposal of furnace waste from steel manufacturing, coal ash disposal, and reclaimer waste disposal (Singh et al. 2011). Singh et al. (2011) finds that 62 percent of the eutrophication impact is a result of power plant waste treatment. On the other hand, Pehnt and Henkel (2009), report that 50 percent of total $\mathrm{EP}$ is a result of $\mathrm{NH}_{3}$ emissions resulting from MEA production and degredation and the other 50 percent is from $\mathrm{NO}_{\mathrm{x}}$ emissions during power production. However, the 
extent of $\mathrm{NH}_{3}$ from MEA degradation is not well documented in the literature and, thus, is a source of significant uncertainty (Pehnt and Henkel 2009). Assumptions regarding transportation of coal also affect the relative contribution from coal transportation in this category, as exemplified by Koornneef et al. (2008) finding that $\mathrm{NO}_{\mathrm{x}}$ emissions from ship transport contribute 80 percent and 60 percent to the nonCCS and CCS cases, respectively. This range of causes and contributors to eutrophication is exemplified in the large range of values reported in the literature.

Eutrophication potential was found to increase in the case of PC with CCS and NG and is the greatest for the case of $\mathrm{PC}$ with CCS and NG with CCS. This is a result of the increased $\mathrm{NO}_{\mathrm{x}}$ emissions resulting from the need for increased fuel (coal and NG) combustion and associated transportation (Tzimas et al. 2007).

While there may be increases, the total EP for coal plants is not large. For reference, the increase in EP, per MWh, presented in Figure 4 is equivalent to fertilizing a 500- $\mathrm{ft}^{2}$ section of lawn. However, the increase in EP due to CCS on a 500-MWe coal plant over the course of a year is equivalent to fertilizing 40 acres. Still, Marx et al. (2011) found that, while EP was found to double in comparison to power plants without CCS, the increase is still very small when compared to total world EP. PC power plants with CCS were found to contribute approximately 1 percent to the total world eutrophication impact (Marx et al. 2011).

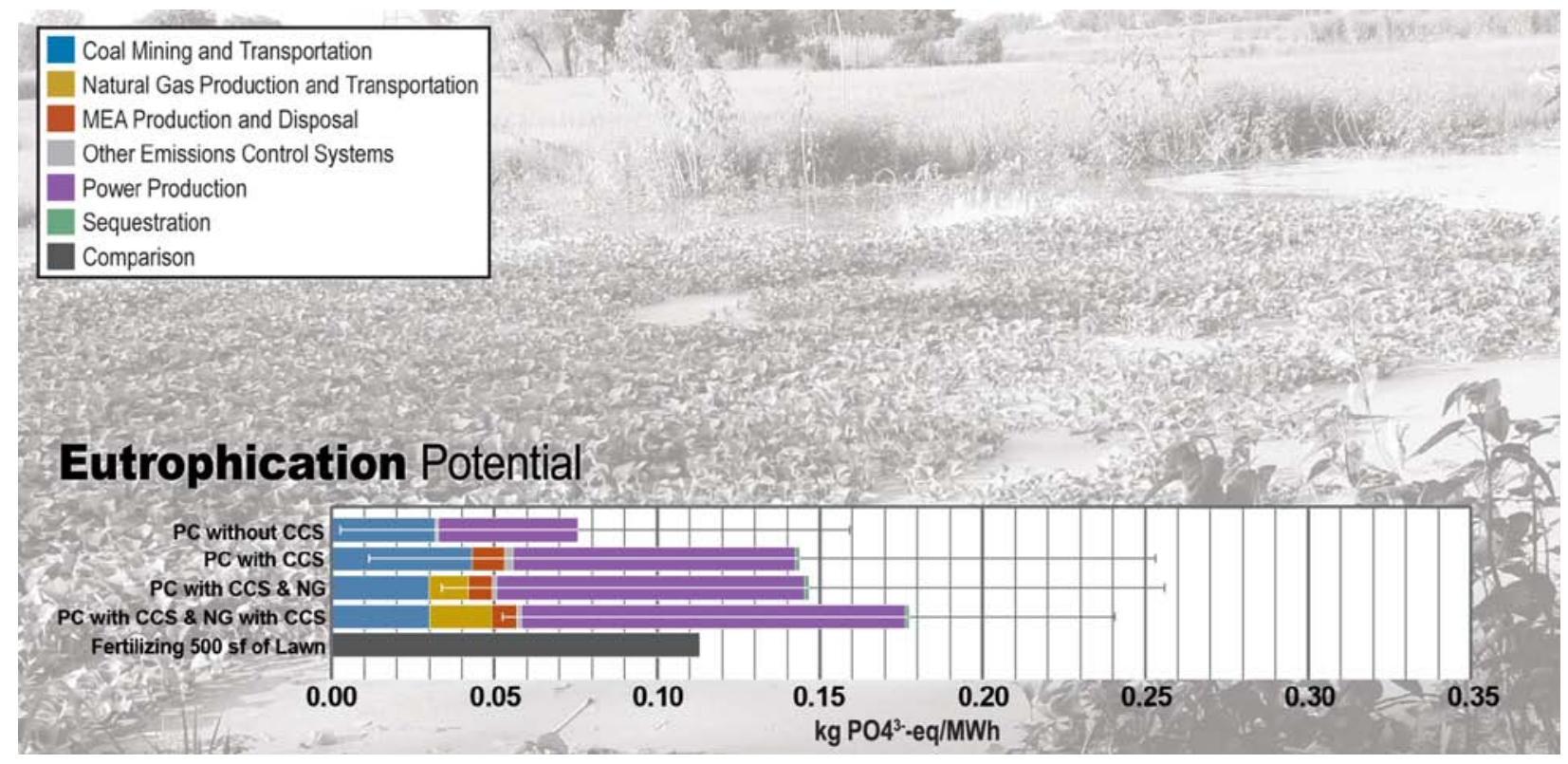

Figure 4. Comparison of Eutrophication Potential. Black lines represent the range of values found in the literature. Fertilizing $500 \mathrm{ft}^{2}$ of lawn is given in units of $\mathrm{kg} \mathrm{PO}_{4}{ }^{3-}$-eq.

\subsubsection{Photo-Oxidant Formation Potential}

Photo-oxidant formation potential (POFP) describes the propensity to produce certain air pollutants that react with sunlight to form reactive chemical compounds, such as ozone, which negatively affect the terrestrial ecosystem (Bare et al. 2003; Lippiatt. 2007). This ground-level pollution is often referred to as "summer smog" (Bare et al. 2003). Some studies showed that POFP will increase will increase as much as 250 percent due to emissions during MEA production and release of MEA to the atmosphere (Viebahn 
et al. 2007; Pehnt and Henkel 2009; Nie et al. 2011). Conversely, Koornneef et al. (2008) show that POFP will decrease due to increased $\mathrm{SO}_{2}$ removal. This diversity of results is indicated by the range of values reported in the literature, shown in the black bars in Figure 5. This large range illustrates the difficulty of assessing POFP. The formation of photo-oxidant smog is based on the chemical interactions between $\mathrm{NO}_{\mathrm{x}}$, hydrocarbons, and sunlight. While the mechanism is well understood, tying specific emissions of $\mathrm{NO}_{\mathrm{x}}$ and hydrocarbons to smog formation, is more difficult due to the importance of the relative quantities of each reactant and other limiting factors (Pehnt and Henkel 2005). Because of this, some studies do not account for the contribution of $\mathrm{NO}_{\mathrm{x}}$ to POFP (Pehnt and Henkel 2005).

Regardless, the total impact of CCS on POFP is small. When compared to total world POFP, PC power plants with CCS were found to contribute 2 percent or less to the total world impact (Marx et al. 2011). By comparison, this is approximately equal to taking 100 cars off the road (Neilsen and Wenzel 2005). Note that the contribution to POFP from NG production and storage for the NG with CCS scenario is zero due to lack of data.

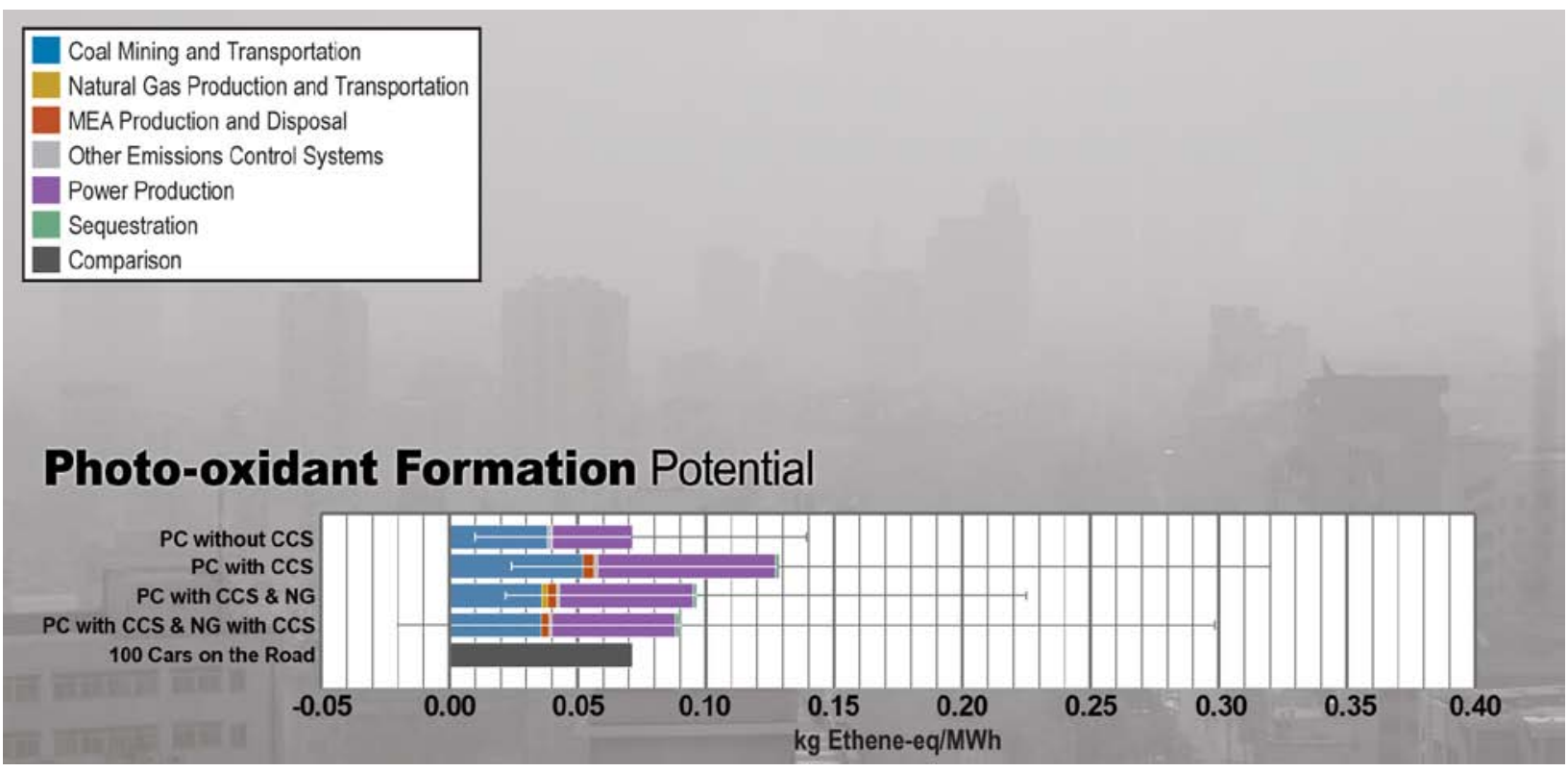

Figure 5. Comparison of Photo-Oxidant Formation Potential. Black lines represent the range of values found in the literature. The emissions associated with 100 cars on the road is given in units of $\mathrm{kg}$ ethene-eq/hr.

\subsubsection{Ecotoxicity Potential}

Ecotoxicity potential (ETP) is related to the impacts of toxic substances on aquatic and terrestrial ecosystems. In the case of PC with CCS, ETP more than doubles, as can be seen in Figure 6. Ecotoxicity potential is assumed to increase due to increased emissions of metals to water and air mainly caused by increased coal combustion, FGD, and steel production (Koornneef et al. 2008). Singh et al. (2011) found increased toxicity of 51 to 205 percent for a PC coal plant with CCS compared to a PC coal plant without. They also showed increases in toxicity of 66 to 413 percent for a NG plant with CCS versus one without. When accounting for increased capture of $\mathrm{NO}_{\mathrm{x}}, \mathrm{SO}_{\mathrm{x}}$, and other emissions in the flue gas, those emissions then enter a waste stream of the plant. Reclaimer wastes and other toxic solid wastes, such as fly ash and boiler ash also contribute (Koornneef et al. 2008). Most studies do not emphasize the ecotoxicity impacts 
of mining, although as the graph below indicates coal production and transportation account for nearly half of ecotoxicity impacts in all cases. The increase in ecotoxicity due to the MEA production stream, coal mining, and increased waste generation is more significant on a regional scale than other categories and could cause adverse externalized impacts in specific locations. However, the overall impact compared to global ecotoxicity impacts is still small (Koornneef et al. 2008); for example, the increase in ETP is approximately equivalent to 10 disposal AA batteries.

However, the ecological toxicity potential is not necessarily indicative of the realized extent of increased ecological damage caused by a process. For example, some models and calculation methodologies account only for the toxicity of emission steams, without consideration of exposure or long-range transport of these emission streams (Rosenbaum et al. 2008). It is not clear from the literature what is included in each estimate of ecotoxicity. However, the large range of ecotoxicity potentials reported suggests some disagreement between methodologies. It will be important to develop a consistent way of assessing actual ecotoxicity damage, including exposures and species transport mechanisms, on different spatial scales of impact to better understand the ecotoxicity impacts of CCS.

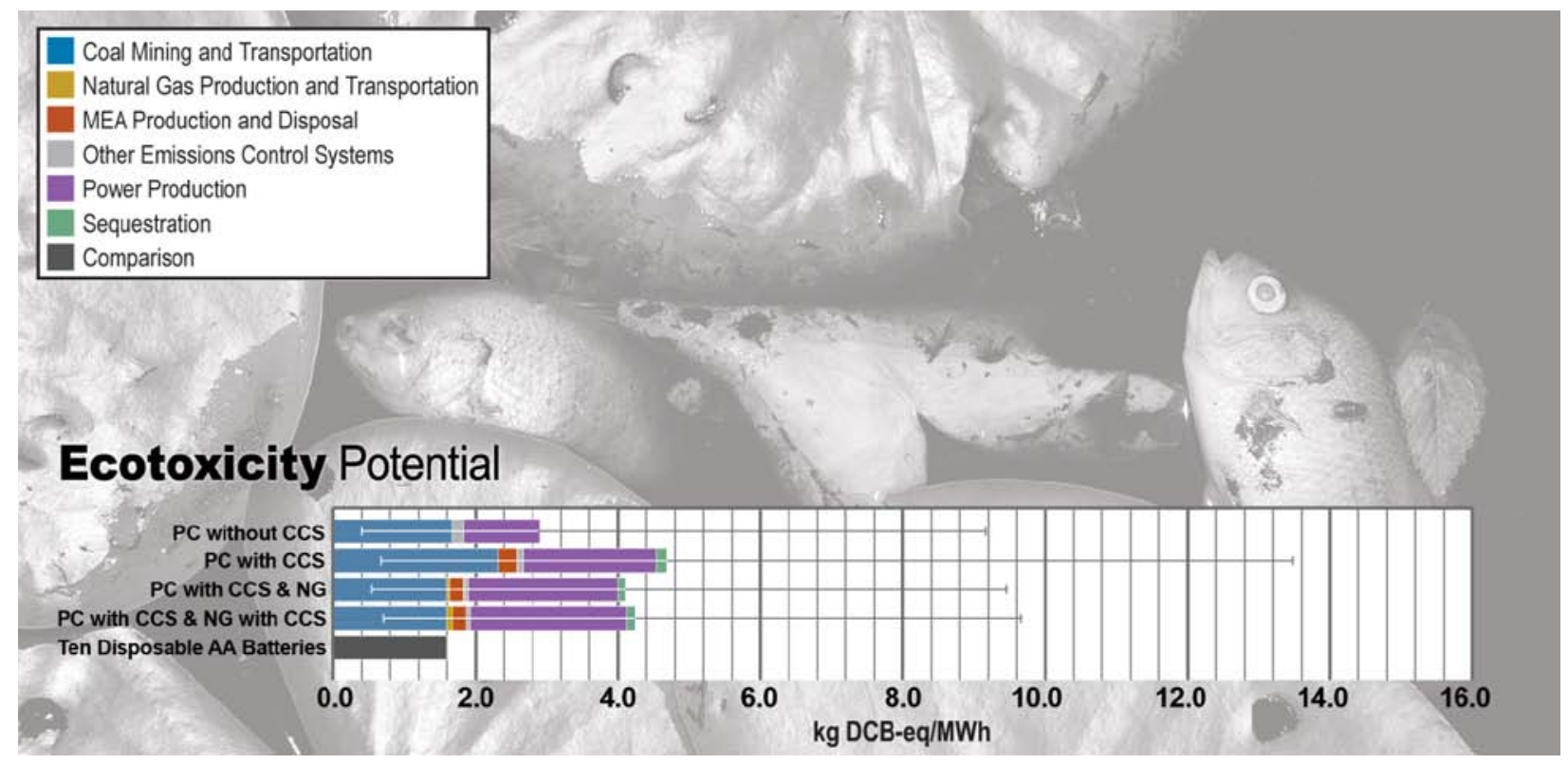

Figure 6. Comparison of Ecotoxicity Potential. Black lines represent the range of values found in the literature. Ten disposable AA batteries is given in units of $\mathrm{kg} \mathrm{DCB}$-eq.

\subsubsection{Human Toxicity Potential}

Impact on human health, quantified by human toxicity potential (HTP), was found to increase significantly for the PC with CCS case. This is caused by ethylene oxide emissions from MEA production and degradation (Koornneef et al. 2008). While MEA consumption during $\mathrm{CO}_{2}$ capture is relatively small in the context of the overall process flows (MEA make-up requirements are approximately $1.5 \mathrm{~kg} /$ metric ton of $\mathrm{CO}_{2}$ absorbed), the high toxicity of ethylene oxide (along with $\mathrm{NH}_{3}$, the main precursor to MEA) results in an increase in toxic potential across the life cycle for the CCS scenario. A study by Koornneef et al. (2008) estimated an increase in HTP by 181 percent, half of which 
is due to emissions related to MEA manufacture, but stressed that this estimate was uncertain due to a lack of data about the MEA production chain. Other contributors include transoceanic coal transport and the power-generating process (Koornneef et al. 2008). Similarly, Viebahn et al. (2007) found an increase of 38 percent due to an increase in PM and cancer-causing airborne emissions, but noted that their study did not consider that some of these flue gas emissions would react with the solvent, which would decrease their emission rates. Pehnt and Henkel (2009) accounted for this and found an increase of only about 25 percent. Some researchers found HTP would decrease due to the $\mathrm{CO}_{2}$ capture system reducing fly ash in flue gas and thus reducing trace metal emissions, HF emissions, and others (Korre et al. 2010). However, any decreases in HTP due to solvent capture, increase ETP because they are now disposed of in the environment (Korre et al. 2010).

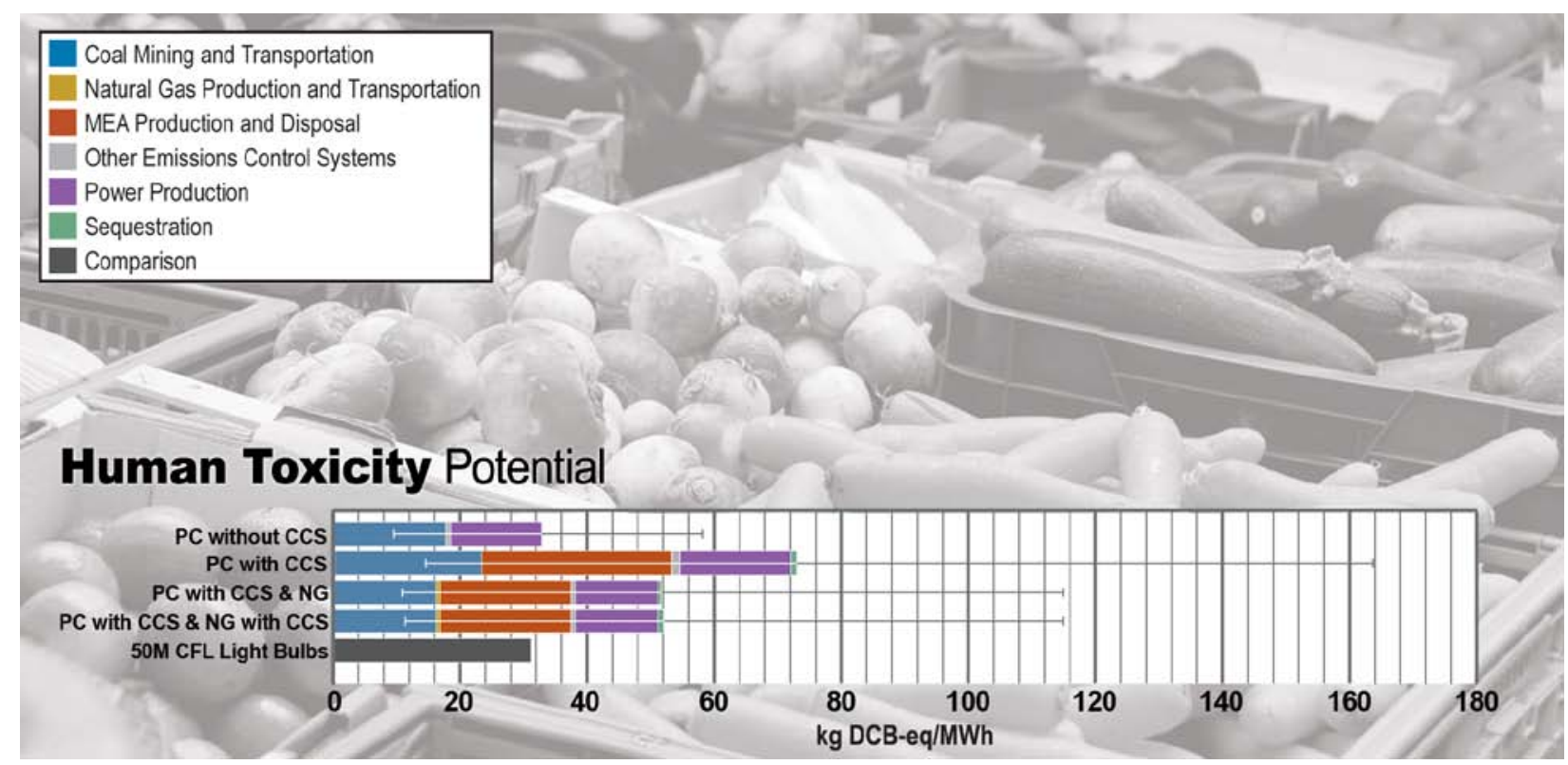

Figure 7. Comparison of Human Toxicity Potential. Black lines represent the range of values found in the literature. 50 million (M) compact fluorescent light bulbs (CFLs) is given in units of $\mathrm{kg}$ DCB -eq.

The increase in HTP is not trivial; it is equivalent to the human health impact of disposing 50 million CFLs (Gestwick et al. 2008; EPA 2010). This suggests that HTP should be a consideration when comparing CCS technologies. Because MEA manufacture contributes significantly to this score, alternative less-toxic solvents or non-solvent-based methods for $\mathrm{CO}_{2}$ separation could be attractive. While these impacts are based on MEA, the results could be extended to other amine-based solvents that depend on a similar production steams. However, similar to ecotoxicity potential, it is important to note that it is not clear if these estimates are indicative of realized health impacts in all cases, as not all models and calculation methodologies consider specific human exposure and dose responses (Rosenbaum et al. 2008; Hertwich et al. 2001). Also, different models may use different characterization or weighting factors to translate from a specific emission mass flow to a realized health impact. The significance of the health impact of PC plants with CCS, specifically the human health risk associated with the MEA production and supply chain, should not be overstated without better understanding of expected exposure routes and dose responses, as well as potential mitigation measures that could or do limit these health risks. However, the large increase in human toxicity potential presented in the literature suggests that this 
impact should not be ignored in future analysis and emphasized the need for further research and better understanding of the assumptions that contribute to the human toxicity potential scores.

\subsubsection{Abiotic Depletion Potential}

Abiotic depletion potential (ADP) describes the depletion of natural, non-renewable resources, including energy resources. Antimony is used as a metric for ADP because it gives a good indication of resource scarcity. Some studies separate use of mineral and other natural resources from energy resources, or treat only natural resources associated with energy production. However, it is important to consider all resources that will be required and used, not just fossil-fuel resources.

In the case of PC with CCS, fossil-fuel depletion is the primary contributor to ADP. These increases are due to the significant energy required to regenerate the MEA solvent and compress the captured $\mathrm{CO}_{2}$ (Rao and Rubin 2002). Most studies find an energy-efficiency penalty around 30 percent for the case of PC with CCS (Koornneef 2007; Rao and Rubin 2002; Zhang et al. 2009). For the NG cases, ADP was not presented and thus is not included in the charts above. Inclusion of ADP for NG plants will increase the total ADP impact for the cases with NG plants (both with and without CCS). It is expected that, with the inclusion of NG consumption, all cases would show a similar level of impact. The amount of fossilfuel resources and limestone will increase proportionally to the increased energy penalty. However, some impacts will not scale directly with increased energy consumption, such as natural resource use for construction of the coal plant and $\mathrm{CO}_{2}$ infrastructure (Koornneef et al. 2008).

In Figure 8, resource use is compared to barrels of oil. Because coal and NG are relatively abundant resources the increase in ADP is not incredibly significant, equivalent to about 1 barrel of oil per MWh (van Oers et al. 2002). The resultant increases in other impact categories caused by an increase in fossil energy consumption are much more significant.

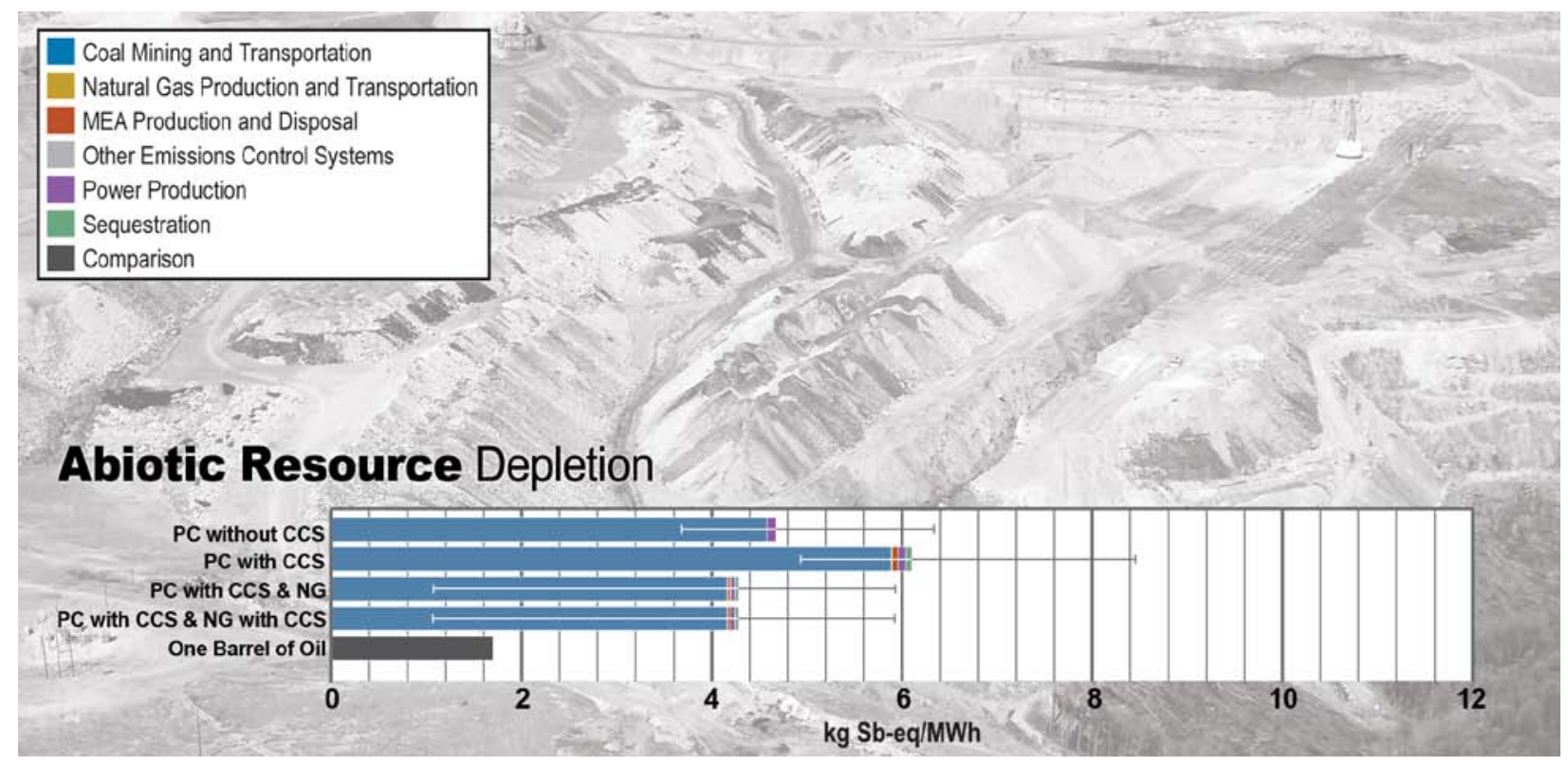

Figure 8. Comparison of Abiotic Depletion Potential. Black lines represent the range of values found in the literature. One barrel of oil is given in units of kg antimony ( $\mathrm{Sb})-\mathrm{eq} / \mathrm{MWh}$. 


\subsubsection{Water Consumption for Power Production}

Application of CCS was found to increase water consumption at the plant by about 100 percent (Black 2010; Koornneef 2008). However, a large range is observed due, probably, to the differences in scope and detail of the reports. No studies were found that characterize total water consumption of coalfired power plants with CCS from an LCA perspective. The water consumption figures presented in Figure 9 are based on the those presented in the NETL Baseline Report (Black 2010), a study by the EPA (Nexant, 2006), and two literature studies (Odeh and Cockerill, 2008; Rao and Rubin, 2002). Water consumption will be an important factor in power generation in the future and is worth treated as an independent metric. Based on current studies, the total water consumption of the coal plant and CCS supply chain is not known and should be considered in future assessments.

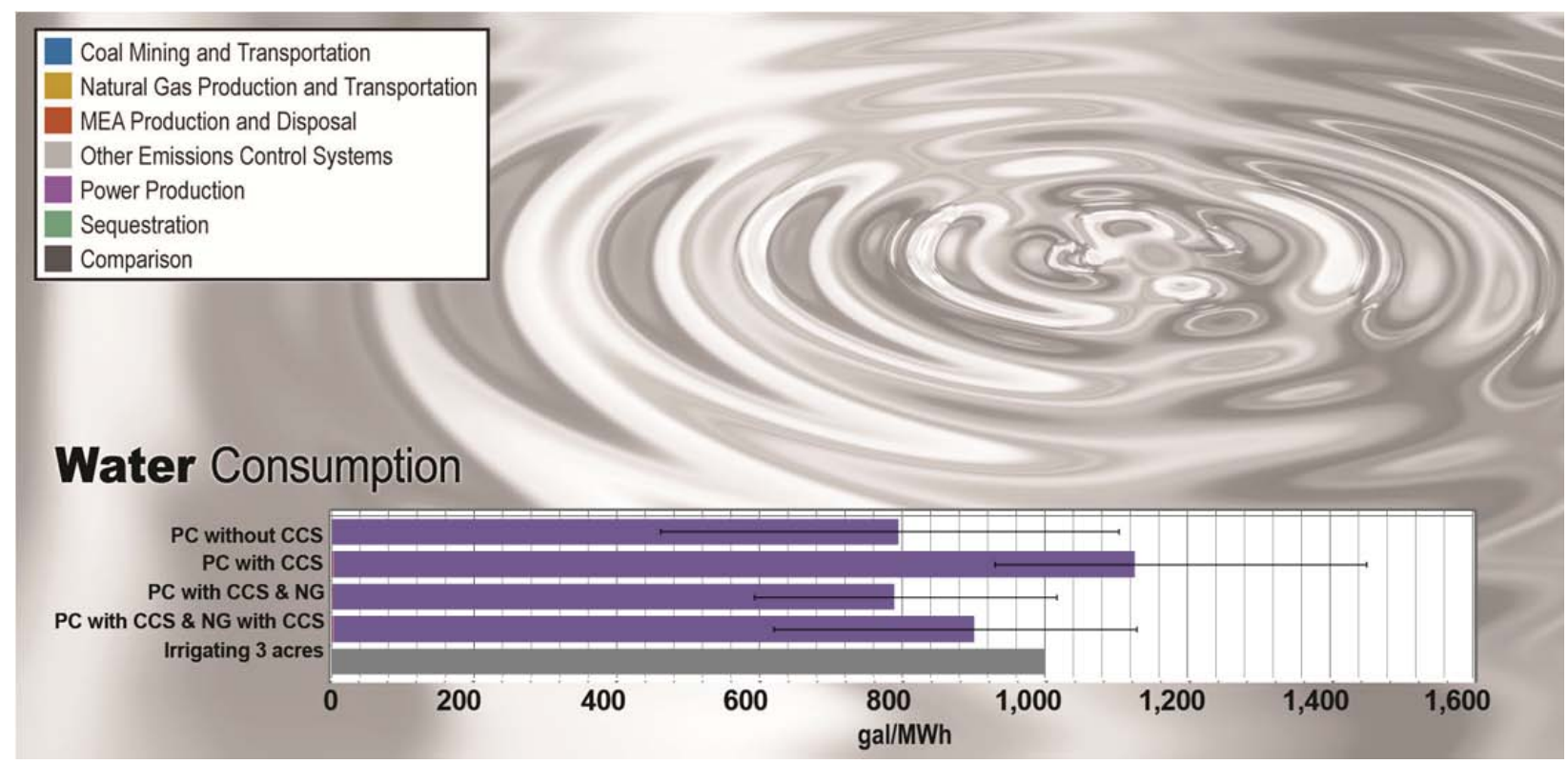

Figure 9. Comparison of Water Consumption from Power Production. Black lines represent the range of values found in the literature. Irrigating 10,000 acres is given in units of gallons $/ \mathrm{hr}$.

\subsection{Supply Chain Impacts}

In recent years, a new dimension in sustainability metrics has begun to emerge from the business logistics community, with support from the intelligence community and government policymakers. This element of sustainability examines supply chain vulnerability. Supply chain vulnerability analysis examines the potential for significant disruption to availability, or dramatic increase in prices, for essential constituent materials or equipment required to produce a product or deliver a service (Wagner and Bode 2006). This approach has proven of particular interest in evaluating emerging technologies that have the potential for dramatic market expansion, resulting in a need to evaluate the consequences of large-scale expansion; or processes/products that depend on so-called "critical" or "strategic" materials, which are essential to an industry sector but available in limited quantities and/or sourced from geopolitically volatile regions of the world. A thorough treatment of how such vulnerability can be measured, and the parameters that influence it, can be found in a 2010 report from the European Commission Ad-Hoc Working Group on Defining Critical Raw Materials (European Commission 2010 ) 
The CCS process and its precursor processes are not critically dependent upon strategically limited mineral resources such as rare earth metals, either as reagents, catalysts, or construction materials. So instead, our supply chain vulnerability analysis examined the potential for supply or market disruptions of MEA that might result from widespread adoption of carbon capture using an MEA-based process. We examined the admittedly extreme scenario of 100 percent adoption of CCS by U.S. coal plants. Assuming that 90 percent of the $\mathrm{CO}_{2}$ generated by the plant(s) was captured and stored, the annual consumption of MEA by U.S. power plants alone would be approximately 3.6 million tons, or 9 times the current U.S. consumption (Nazir-Narir 2011; Global Market Analysts 2010). Although 100 percent adoption of CCS by U.S. coal plants is not a realistic scenario, the exercise illustrates that the potential magnitude of the MEA demand created by more realistic adoption rates - for instance, 10 percent of existing plantsis comparable to the total current U.S. demand for MEA. This suggests some potential for significant market disruptions in the ethanolamines market, particularly in the event of a rapid deployment of CCS in the power industry.

Such disruption potential appears less likely in the case of the chief chemical precursors to MEAethylene oxide and ammonia. This is because MEA manufacture represents a relatively minor load on their very high worldwide production capacity. Approximately 6 percent of world ethylene oxide supply currently is used in the manufacture of ethanolamines, and the percentage of world $\mathrm{NH}_{3}$ supplies going to this process is even lower. 


\subsection{Conclusions}

Based on the results of the review of the LCA literature regarding the sustainability impacts of adding CCS capability to coal-fired power plants, using conventional post-combustion MEA-based $\mathrm{CO}_{2}$ capture, several general conclusions can be drawn. This section presents the significant findings from that review, including the main impact categories for PC coal plants with CCS and potential opportunities for future research.

\subsection{Main Impact Categories for CCS}

Carbon capture and sequestration via post combustion MEA processing can achieve about a 70 percent reduction of global warming gases using existing technology. However, this reduction does not come without a cost in some other sustainability impact categories. Specifically, the impact on human toxicity and ecotoxicity were shown to be potentially significant and could have more severe impacts on a regional or local scale, warranting better understanding of actual realized effects on ecological degradation and human health risk. Most other environmental and human health impact categories increase only slightly on a global scale. Although the external environmental and human health impacts may be small when compared to global resource flows and environmental depletion, they are still important to consider when comparing technologies because they can provide insight into opportunities for improving technologies and areas for future research.

Based on the results of previously published LCAs and process analyses, the dominant factors in determining the sustainability impacts of the carbon capture step is the parasitic energy required to regenerate the MEA solvent and recover the $\mathrm{CO}_{2}$ stream and impact from production, degradation, and disposal of the MEA solvent. While other factors contributed, they were not deemed to be significant in the overall sustainability assessment.

The environmental impacts of this parasitic energy derive mostly from the marginal increase in energy-related wastes associated with creating the parasitic energy (i.e., from resource extraction, fuel transportation, and combustion of the additional fuel required to operate the CCS unit). This includes increases in abiotic resource depletion, eutrophication, acidification, human toxicity potential, and ecotoxicity potential. These increases in environmental impact categories are caused by increased coal and limestone mining, increased $\mathrm{NO}_{\mathrm{x}}$ generation, and increased toxic metal emissions, primarily in fly ash and boiler ash.

Also of note are the relative impacts based on the source of the parasitic power, namely whether the parasitic power was supplied by a similar PC plant with CCS, a NG plant, or NG plant with CCS. In all impact categories, except GWP, producing the requisite parasitic power with a similar PC plant with CCS resulted in a higher environmental or human health impact. In the case of supplying any additional power with a NG plant, the environmental impacts were typically more than that of the baseline coal plant, but less than the coal plant with CCS. This is the case for EP, ETP, HTP, and POFP. However, Singh et al. (2011) find that putting CCS on the NG plant as well significantly increased the toxicity potential of the NG plant. This seemingly large change is not seen in the data presented in Figures 6 and 7 because the data above are an average of the literature values and because the impact associated with the NG plant is only a small portion of the impact, equivalent to the parasitic power requirement or decrease in energy efficiency of the plant. However, this may suggest that capturing the carbon from NG plants is not 
justified given the increase in other impact categories per $\mathrm{kg} \mathrm{CO}_{2}$-eq captured. The studies reviewed seem to suggest that PC power plants with supplemental energy provided by an NG plant without CCS appeared to be the least impactful option. However, the data set, especially concerning NG, is incomplete and should not be used to draw firm conclusions.

Because many of the negative sustainability impacts of CCS are in directly related to the amount and source of parasitic energy that must be generated, some of these impacts can be mitigated by some combination of the following strategies:

- using non-fossil (e.g., solar, geothermal, wind) energy to drive the regeneration process;

- using relatively "clean" and/or low-carbon fossil sources such as natural gas to supply the regeneration heat; and

- using heat pumps, and effective heat integration within the overall plant, to reduce the requirement for high-grade energy for the regeneration step.

Aside from the environmental impacts associated with the parasitic energy load, some additional sustainability impacts were noted by some of the studies we considered. Notable among these was an increase in the human toxicity potential resulting from the production of MEA under the CCS scenario. This suggests the potential for using less toxic solvents or potentially non-solvent-based $\mathrm{CO}_{2}$ capture systems. Also worth noting are the increased eutrophication and acidification impacts associated with MEA degradation products, specifically $\mathrm{NH}_{3}$ emissions. Supply chain impacts were not observed to be a concern for CCS with MEA solvent, but should be considered for other technologies with different material inputs.

\subsection{Data Gaps and Areas for Further Research}

As is often the case with LCA studies drawn from multiple sources, differences in the study scope, goals, and underlying assumptions tend to complicate the direct comparison or aggregation of data. As has been previously reported, the variability between studies can be quite large, even for core metrics of performance such as the reduction in GHG potential (Sathre 2011). Thus, the results presented here should be treated as provisional data, which accurately reflect the findings of the cited studies, but have not yet been harmonized to a common baseline. Specifically, many studies compare carbon capture scenarios to a PC without CCS baseline, but do not provide disaggregated data for the component processes of the PC baseline case. As a result, there is less confidence in the percentage contributions from each process in the PC base case than for the other cases. Discrepancies were also observed in the contribution from coal production compared to combustion from different studies. Some differences stem from the allocation of transportation impacts or setting of boundaries, but the source of all discrepancies is unclear from the studies. Another contributor to the disagreement of values or trends reported in the literature could be uncertainty in the underlying data. For example, there is significant uncertainty with respect to emissions from MEA degradation, which impact the EP of all cases with CCS (Pehnt and Henkel 2009; Veltman et al. 2010).

There are also limited data for NG with and without CCS that have been disaggregated based on component process. Most studies that have evaluated NG plants with and without CCS have looked at the overall impacts of the plant. Of the studies that include NG plants with and without CCS, most evaluated only a limited number of environmental metrics, primarily focusing on GWP. The impact of 
NG plants providing only the parasitic power requirement for coal plants with and without CCS has not been extensively studied in the literature. Some studies de-rate the coal plant. Even studies that assume the parasitic power consumption is provided by a NG plant do not disaggregate the impacts of the NG plant from those of the coal plant, thus, the relative impacts of the NG plant are impossible to discern. Typically, the impacts on an independent NG plant are presented, which must be scaled and combined with the impact of the coal plant. A better understanding of the contributions of just the parasitic energy load of a PC plant with CCS would allow for modeling and assessment of the improvement from increased efficiency or alternative energy sources to provide supplemental power for the parasitic load.

In an integrated assessment framework, it would also be useful to understand the specific impacts of other emissions control technologies. That way the sustainability costs and benefits of integrated emissions technologies could be evaluated. However, current literature does not include data on the impact of other emissions control technologies, for example SCR, FGD, or particulate control technology; these are included with the coal plant emissions.

Also, the current literature does not give sufficient weight to water consumption life-cycle data. Water quality and degradation is incorporated into the TRACI metrics, but not specific water consumption or withdrawal data. Water consumption should be its own category due to the importance of water withdrawal and consumption rates for power production, especially in dry climates. Current data presented in this report only addresses water use at the plant.

In addition, most studies assume normal operation in that they do not account for the potential impacts of equipment failures, accidental releases, or other events. Viebahn et al. (2007) find that potential for $\mathrm{CO}_{2}$ leakage or release from the final sequestration site can significantly affect the potential for decreased GHG emissions. This is also affected by the time scale chosen for analysis. Some LCAs end their analyses at the point where $\mathrm{CO}_{2}$ is injected into the sequestration well, thereby eliminating the need to determine the rate of leakage or sequestration timeframe. Quantifying the $\mathrm{CO}_{2}$ leakage rates and accounting for them in the assessment is a difficult task and requires a number of assumptions for which there is not good data to base the assumption on. For example, little is known about the potential leakage rates of sequestration sites. Some believe that, once injected, $\mathrm{CO}_{2}$ will not resurface for a long period of time or could even be sequestered forever (IPCC 2005; Shafer and Brantley 2011). Others disagree, claiming that there is potentially significant risk of slow or catastrophic releases of $\mathrm{CO}_{2}$ from sequestration sites (Viebahn et al. 2007; Pehnt and Henkel 2009). With any new technology, there is always some risk. In this case, there is risk that all captured $\mathrm{CO}_{2}$ will not remain captured permanently. However, at the moment, an expectant or reasonable leakage rate is not known (Viebahn et al. 2007). The IPCC report acknowledges that "if continuous leakage of $\mathrm{CO}_{2}$ occurs it could at least in part offset the benefits of CCS for mitigating climate change" (IPCC 2005). Viebahn et al. (2007) performed a sensitivity analysis of the global warming impact of fossil-fuel power plants with CCS technologies based on varying the leakage rate of $\mathrm{CO}_{2}$ from sequestration sites from 0.1 to 0.0001 percent per year. In the case of a 0.1 percent annual leakage rate, all the stored $\mathrm{CO}_{2}$ would be released after 6,000 years. With lower leakage rates, the time scale of $\mathrm{CO}_{2}$ release extends to 10,000 years or more. However, in all leakage-rate scenarios assumed, all the stored $\mathrm{CO}_{2}$ escaped eventually (Viebahn et al. 2007). Wilson and Monea (2004) modeled the most probable release rates of $\mathrm{CO}_{2}$ into the atmosphere and found and estimated 0.2 percent of total stored $\mathrm{CO}_{2}$ would leak after 5,000 years, with a 95 percent confidence interval from 0.005 percent to 1.3 percent. This points to the fact that LCA does not have a mechanism to account for time scales or weigh emissions that occur at different points in time. If leakage is assumed in a LCA of CCS, a defensible method for discounting future emissions or an appropriate analysis timeframe 
needs to be established. For example, through climate modeling, one could determine appropriate weighting factors for future $\mathrm{CO}_{2}$ emissions based on their anticipated impact at the time of release, compared to the relative impact of $\mathrm{CO}_{2}$ emissions today. Or, similar models could determine an appropriate time scale for analysis, for example 10,000 years.

In a different scenario, the expected $\mathrm{CO}_{2}$ leakage under design conditions could be reasonably anticipated to be zero. However, there is always risk that design conditions will change based on catastrophic natural events, like an earthquake, or long-term changes in the permeability and sequestration characteristics of given site. Or, the $\mathrm{CO}_{2}$ pipeline architecture could fail, causing large releases of concentrated $\mathrm{CO}_{2}$ locally. These types of accidental releases are more difficult to predict, but may dramatically increase the environmental and social impacts of CCS. Pehnt and Henkel (2009) discuss the different mechanisms for potential $\mathrm{CO}_{2}$ leakage and differentiate them into two categories: 1) local-scale damage and 2) global-scale damage. Global-scale damage consists primarily of the type of leakage described above, which occurs over long time scales and disparate spatial scales. Local-scale damage, on the other hand, occurs suddenly and/or in a specific location. Examples of local-scale damage are leaking $\mathrm{CO}_{2}$ or $\mathrm{CO}_{2}$-loaded acid brine endangering nearby drinking water supplies by mobilizing contaminants in nearby rock formations or leaking into the deep sea and damaging marine ecosystems. Another example of local-scale damage is the risk of large, sudden releases of $\mathrm{CO}_{2}$ from compromised sequestration sites or pipelines, which could result in toxic and potentially lethal $\mathrm{CO}_{2}$ concentrations in a small geographic location (Viebahn et al. 2007). The impacts of local-scale damage may, overall, be smaller than the damage caused by global-scale impacts in the mass of $\mathrm{CO}_{2}$ released and total geographic damage. However, local scale impacts may impact fewer people or organisms more strongly (Pehnt and Henkel 2009). Life-cycle analysis and other similar analyses also do not address or have a mechanism to weigh the differences in spatial scales when addressing the severity of impact. The number of persons or organisms affected and the magnitude or impact may be two important factors when attempting to compare these two types of impacts. This could also be applied to the ecotoxicity and human toxicity impact categories to provide a better understanding of magnitude and severity of impact.

Whether global or local, $\mathrm{CO}_{2}$ leakage or release would negate some of the potential for $\mathrm{CO}_{2}$ decrease, and increase, at least, the acidification, ecotoxicity, and human toxicity potential of CCS. An integrated sustainability assessment for CCS technologies should be developed to include all stages of the process chain, from mining and extraction to sequestration, and the mechanisms for evaluating risk and time scales. If the full life-cycle impacts of CCS are to be accounted for, it will be important to quantify appropriately the impacts associated with potential $\mathrm{CO}_{2}$ leakage or release.

Related to the risk of additional impacts associated with $\mathrm{CO}_{2}$ sequestration, the public perception of that risk is also an important factor to account for when assessing the feasibility of any CCS project. While the legal and regulatory framework may be able to accommodate complex licensing and liability requirements associated with CCS (Reitze and Ternes 2011), public acceptance and public perception of CCS may be an important issue that demands further exploration in conjunction with other environmental risks (Curry et al. 2005).

Additional and more robust data sets will allow researchers and policymakers to draw strong conclusions with respect to the specific relative impact of different CCS technologies and can suggest places to focus our efforts to achieve technically feasible, economically viable, and environmentally conscious energy-generation technologies for maximum impact. In addition, indentifying methods within the LCA framework to address issues of technical and political risk, including the weighting of emissions 
based on temporal and spatial scales to determine the relative risk of environmental impact from carbon sequestration, will build a more comprehensive assessment of true impactors of the sustainability of CCS and will aid in identifying potential environmental, social, or risk-related issues that could impede the large-scale deployment of CCS or other energy-generation technologies. 


\subsection{Resources}

Bare J, G Norris, D Pennington, and T McKone. 2003. "TRACI: The Tool for the Reduction and Assessment of Chemical and Other Environmental Impacts." Journal of Industrial Ecology 6:49-78. doi: $10.1162 / 108819802766269539$.

Black J. 2010. "Cost and Performance Baseline for Fossil Energy Plants; Volume 1: Bituminous Coal and Natural Gas to Electricity." DOE/NETL-2010/1397, prepared by the National Energy Technology Laboratory (NETL) for the U.S. Department of Energy, Pittsburg, Pennsylvania.

Brundtland, G. 1987. “Our common future.” Oxford: Oxford University Press.

Curry T, DM Reiner, S Ansolabehere, and HJ Herzog. 2005. "How aware is the public of carbon capture and storage." In: Proceedings of the 7th International Conference on Greenhouse Gas Control Technologies, Vol. I Elsevier, London, UK, pp. 1001-1009.

Energy Information Administration. 2010. “2010 Annual Energy Review: Total Energy Consumption.” Available at: http://www.eia.gov/totalenergy/data/annual/

European Commission Ad-Hoc Working Group on Defining Critical Raw Materials. 2010. "Critical Raw Materials for the EU.” European Commission: Enterprise and Industry, Brussels, Belgium.

Gestwick M, E Cubi, G Doluweera, and S Goodarzi. 2008. “A Ban on Incandescent Lamps? An Analysis of the Proposed NRCan Lighting Standard." In: Proceedings of the U.S. Association of Energy Engineers. Available

at: http://www.usaee.org/usaee2008/submissions/OnlineProceedings/Gestwick\%20et\%20al\%20Paper . $\mathrm{pdf}$

Global Industry Analysts. 2010. "Ethanolamine: A Global Strategic Business Report.” April 2010 Market Report. Available at: http://www.companiesandmarkets.com/Summary-MarketReport/ethanolamine-a-global-strategic-business-report-289263.asp.

Hertwich, E. G., Mateles, S. F., Pease, W. S. and McKone, T. E. 2001. "Human toxicity potentials for life-cycle assessment and toxics release inventory risk screening." Environmental Toxicology and Chemistry, 20: 928-939. doi: 10.1002/etc.5620200431

Institution of Chemical Engineers (IChemE). 2002. The Sustainability Metrics: Sustainable Development Progress Metrics Recommended for Use in the Process Industries. Rugby, United Kingdom. Available at: $\underline{\text { http://nbis.org/nbisresources/metrics/triple_bottom_line_indicators_process_industries.pdf }}$

Intergovernmental Panel on Climate Change (IPCC). 2007. "Summary for Policymakers." Climate Change 2007: The Physical Science Basis. Contribution of Working Group I to the Fourth Assessment Report of the Intergovernmental Panel on Climate Change. Available at: http://www.ipcc.ch/pdf/assessment-report/ar4/wg1/ar4-wg1-spm.pdf.

Intergovernmental Panel on Climate Change (IPCC). 2005. "Special Report on Carbon Capture and Storage." Prepared by Working Group III for the Intergovernmental Panel on Climate Change. Available at: http://www.ipcc-wg3.de/publications/special-reports/special-report-on-carbon-dioxidecapture-and-storage 
International Organization for Standardization (ISO). 2006. "Environmental Management - Life Cycle Assessment - Requirements and Guidelines.” ISO 14044, Geneva, Switzerland.

Koornneef J, T van Keulen, A Faaij, and W Turkenburg. 2008. "Life cycle assessment of a pulverized coal power plant with post-combustion capture, transport and storage of $\mathrm{CO}_{2}$." International Journal of Greenhouse Gas Controls 2:448-467.

Korre A, Z Nie, and S Durucan. 2009. "Life cycle modeling of fossil fuel power generation with postcombustion $\mathrm{CO}_{2}$ capture.” International Journal of Greenhouse Gas Control 4:289-300.

Lippiatt B. 2007. "Building for Environmental and Economic Sustainability: Technical Manual and User Guide.” NISTIR 7423, National Institute of Standards and Technology, Gaithersburg, Maryland.

Manuilova A, J Suebsiri, and M Wilson. 2009. "Should Life Cycle Assessment be part of the Environmental Assessment? Case study: EIA of $\mathrm{CO}_{2}$ capture and storage in Canada." Energy Procedia 1:4511-4518.

Marx J, A Schreiber, P Zapp, M Haines, J-Fr Hake, and J. Gale. 2011. "Environmental evaluation of CCS using Life Cycle Assessment - a synthesis report.” Energy Procedia 4:2448-2456.

Nazir-Nazir A. 2011. "Ethanolamine Market Study and Process Evaluation." Accessed via the web at: http://www.scribd.com/doc/48721921/Executive-Summary August, September 2011.

Neilsen P and H Wenzel. 2005. "Environmental Assessment of Ethanol Produced from Corn Starch and Used as an Alternative to Conventional Gasoline for Car Driving." Dissertation, Institute for Product Development, Technical University of Denmark, Lyngby, Denmark. Available at: www.ipu.dk/upload/publikationer/bio-ethanol-report.pdf

Nexant Inc. 2006. "Environmental Footprint and Costs of Coal-Based Integrated Gasification Combined Cycle and Pulverized Coal Technologies." EPQ-430/R-06/006, U.S. Environmental Protection Agency. Cincinnati, Ohio.

Nichols C, J Eppink, M Marpuis, and L Manfredo. 2009. “Coal-Fired Power Plants in the United States: Examination of the Costs of Retrofitting with $\mathrm{CO}_{2}$ Capture Technology and the Potential for Improvements in Efficiency." DOE/NETL-402/102309, National Energy Technology Laboratory. Pittsburgh, Pennsylvania.

Nie Z, A Korre, and S Durucan. 2011. "Life cycle modeling and comparative assessment of the environmental impacts of oxy-fuel and post-combustion $\mathrm{CO}_{2}$ capture, transport and injection process." Energy Procedia 4:2510-2517.

Odeh NA and TT Cockerill. 2008. "Life cycle GHG assessment of fossil fuel power plants with carbon capture and storage.” Energy Policy 36:367-380.

Pehnt M and J Henkel. 2009. "Life Cycle Assessment of Carbon Dioxide Capture and Storage form Lignite Power Plants.” International Journal of Greenhouse Gas Control 3:49-66.

Rao A and E Rubin. 2002. "A Technical, Economic, and Environmental Assessment of Amine-Based $\mathrm{CO}_{2}$ Capture Technology for Power Plant Greenhouse Gas Control.” Environ. Sci. Technol. 36:44674475. 
Reitze A and M Ternes. 2011. "Navigating the Legal Landscape." Chemical Engineering Progress (CEP) AIChE 107(8): 45-49.

Rosenbaum, R., Bachmann, T., Gold, L., Huijbregts, M., Jolliet, O., Juraske, R., Koehler, A., Larsen, H., Macleod, M., Margni, M., Mckone, T., Payet, J., Schuhmacher, M., Van De Meent, D., and Hauschild, M. 2008. "USEtox - the UNEP-SETAC toxicity model: recommended characterisation factors for human toxicity and freshwater ecotoxicity in life cycle impact assessment". The International Journal of Life Cycle Assessment 13:532-46.

Sathre, R. 2011. "The Role of Life Cycle Assessment in Identifying and Reducing Environmental Impacts of CCS.” LBNL-4548E, Lawrence Berkeley National Laboratory, Berkeley California. Retrieved from: http://escholarship.org/uc/item/2bv98328

Schwartz J, B Beloff, and E Beaver. 2002. "Use Sustainability Metrics to Guide Decision-Making." Chemical Engineering Progress (CEP) AIChE 98(7): 58.

Scientific Certification Systems. 2011. "Life-Cycle Stressor-Effects Assessment (LCSEA) GHG Accounting Framework." Annex B of SCS-002 of National Standard, Committee Draft. Scientific Certification Systems. Available at: http://www.scscertified.com/docs/SCS002AnnexB_120409_CD.pdf

Shafer J and D Brantley. 2011. "Characterizing a Geologic Formation.” Chemical Engineering Progress (CEP) AIChE 107(8): 50-52.

Singh B, A Strømman, and E Hertwich. 2011. "Comparative impact assessment of CCS portfolio: Life cycle perspective.” Energy Procedia 4:2486-2493.

Spath, P. L.; Mann, M. K. 2004. "Biomass Power and Conventional Fossil Systems with and without CO2 Sequestration -- Comparing the Energy Balance, Greenhouse Gas Emissions and Economics." Report No. TP-510-32575. National Renewable Energy Laboratory. Golden, Colorado

Toffoletto L, C Bulle J Godin, C Reid, and L Deschenes. 2007. "LUCAS-A New LCIA Method Used for a Canadian-Specific Context." IntJ LCA 12(2):93-102.

Tzimas E, A Mercier, C Cormos, and S Peteves. 2007. "Trade-off in emissions of acid gas pollutants and of carbon dioxide in fossil fuel power plants with carbon capture." Energy Policy 35:3991-3998.

U.S. Environmental Protection Agency (EPA). 2000. "Emissions Facts: Average Annual Emissions and Fuel Consumption for Passenger Cars and Light Trucks." EPA420-F-00-013, Cincinnati, Ohio. Available at: http://www.epa.gov/oms/consumer/f00013.pdf

U.S. Environmental Protection Agency (EPA). 2011. "Inventory of U.S. Greenhouse Gas Emissions and Sinks: 1990-2009.” EPA430-R-11-005. Washington, D.C. Available at: http://epa.gov/climatechange/emissions/downloads11/US-GHG-Inventory-2011Complete_Report.pdf

U.S. Environmental Protection Agency (EPA). 2010. "Frequently Asked Questions: Information on Compact Fluorescent Light Bulbs (CFLs) and Mercury." Cincinnati, Ohio. Available at: http://www.energystar.gov/ia/partners/promotions/change light/downloads/Fact Sheet Mercury. pdf 
van Oers L, dA e Koning, J Guinee, and G Huppes. 2002. “Abiotic Resource Depletion: Improving Characterization Factors for Abiotic Resource Depletion in LCA.” Road and Hydraulic Engineering Institute of the Dutch Ministry of Transport, Public Works and Water Management (V\&W), Delft, The Netherlands. Available at: http://www.leidenuniv.nl/cml/ssp/projects/abioticdepl.html

Veltman K, B Singh, and E Hertwich. 2010. "Human and Environmental Impact Assessment of Postcombustion $\mathrm{CO}_{2}$ Capture Focusing on Emissions from Amine-Based Scrubbing Solvents to Air." Environ. Sci. Technol. 44:1496-1502.

Viebahn,P, J Nitsch, M Fischedick, A Esken, D Schuwer, N Supersberger, U Zuberbuhler, and O Edenhofer. 2007. "Comparison of carbon capture and storage with renewable energy technologies regarding structural, economical, and ecological aspects." International Journal of Greenhouse Gas Control 1(1):121-133.

Wagner SM and C Bode. "An Empirical Investigation into Supply Chain Vulnerability." Journal of Purchasing and Supply Management 12:301-312.

Wilson $\mathrm{M}$ and $\mathrm{M}$ Monea (eds.). 2004. "IEA GHG Weyburn $\mathrm{CO}_{2}$ monitoring \& storage project Summary report 2000-2004.” Petroleum Technology Research Centre, Regina, Canada.

Wright M, D Allen, R Clift, and H Sas. 1997. "Measuring Corporate Environmental Performance: The ICI Environmental Burden System.” Journal of Industrial Ecology 1(4):117-127.

Zhang J, L Basson, and M Leach. 2009. "Review of life cycle assessment studies of coal-fired power plants with carbon capture and storage." Proceeding of International Conference of Sustainable Power Generation and Supply, SUPERGEN'09. Nanjing, China. IEEE. 


\section{Distribution}

No. of

Copies

\# Local Distribution

Pacific Northwest National Laboratory Mike Elliott

Charlie Freeman

Sarah Widder

Scott Butner

Name
No. of

Copies
Mailstop

Mailstop

Mailstop

Mailstop

(PDF)

Distr.1 




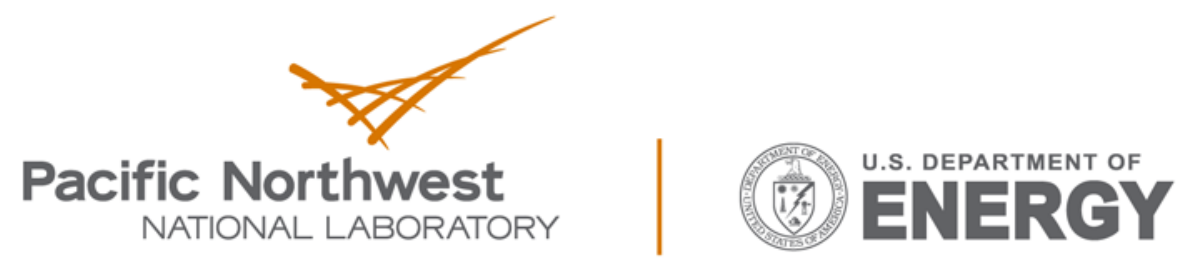

Proudly Operated by Battelle Since 1965

902 Battelle Boulevard

P.O. Box 999

Richland, WA 99352

1-888-375-PNNL (7665)

www.pnnl.gov 